\title{
Design aspects of solid state fermentation as applied to microbial bioprocessing
}

\begin{abstract}
Solid state fermentation (SSF) refers to the microbial fermentation, which takes place in the absence or near absence of free water, thus being close to the natural environment to which the selected micro organisms, especially fungi, are naturally adapted. SSF has been used in the world for a long time. This technology is commonly known in the East, for traditional manufacture of fermented foods, and in the west, for mould-ripened cheese. It can be defined as a system, in which the growth of selected microorganism(s) occurs on solid materials with low moisture contents and has been identified as a potentially important methodology and technique in biotechnology. Nowadays, SSF is an economically viable, practically acceptable technology for large-scale bioconversion and biodegradation processes. Development of sustainable SSF and bioprocess technology is an emerging, multidisciplinary field with possible application to the production of enzymes, chemicals, bioethanol and pharmaceuticals. SSF offers many advantages over conventional submerged fermentation (SMF) such as, simple and inexpensive substrates, elimination of the need for solubilisation of nutrient from within solid substrates, elimination of the need for rigorous control of many parameters during fermentation, product yields are mostly higher, lower energy requirements, produce less waste water, no foam generation and relatively easy recovery of end products. SSF provides flexibility in terms of the raw materials to be used and their capability to produce various value-added products.
\end{abstract}

Keywords: solid state fermentation, submerged fermentation, biological factors, physico-chemical factors, bioreactors, mass transfer phenomena, polyurethane foam
Volume 4 Issue I - 2017

\author{
Musaalbakri Abdul Manan, ${ }^{1,2}$ Colin Webb ${ }^{2}$ \\ 'Malaysian Agricultural Research and Development Institute \\ (MARDI), Malaysia \\ ${ }^{2}$ Department of Chemical Engineering and Analytical Science, \\ University of Manchester, UK
}

\author{
Correspondence: Colin Webb, School of Chemical \\ Engineering and Analytical Science, University of Manchester, \\ Oxford Road, Manchester MI3 9PL, UK,
}

Email colin.webb@machester.ac.uk

Received: August 14, 2017| Published: October 17, 2017

\section{Introduction}

Solid state fermentation (SSF) has been practiced for centuries in the Orient and Asian region in both large and small scale applications in food processing and production of traditional fermented foods. Products such as fermented soybean (tempe, soy sauce, annatto, miso, etc) and fermented rice (tapai, koji, red fermented rice, brewing of the Japanese rice wine (sake)) among others are based on SSF. Some of these products have been in existence for over a thousand years, and their production was probably based on trial and error methods. Bread making is one of the oldest techniques known to man, and archaeological discoveries indicate that ancient Egyptians were making bread using a fermentation process even as early as $2600 \mathrm{BC} .^{1}$ Fermented foodstuffs serve as an important component in the daily diet of a large majority of the families in that region as a source of protein and vitamins. However, the low level of traditional technology in the preparation of these products, the various sanitary requirements, the lack of built-in safeguards against undesirable microbial growth and toxins and other closely related constraints pose challenging problems to scientific and technological workers. There is therefore a perceived need for more basic understanding, in-depth studies and scientific as well as technological research on the various aspects of SSF. The process of SSF has been practiced since ancient times and most of the processes are still practiced without any major modifications. The techniques applied are very simple, principally needing only raw materials, simple pre-treatment of the substrate to be fermented and microorganisms as an inoculum. The fermentation process proceeds at room temperature. Table 1 shows the development of SSF from the past to the present and future. SSF technology has contributed many products for humans since the beginning of human civilisation. ${ }^{2}$
In recent years, the application and development of SSF technology has greatly expanded especially in Western countries because of its perceived advantages in the production of various secondary metabolites and novel foods. ${ }^{3}$ Detailed studies carried out in laboratories have helped to understand and to confirm the chemical and microbiological changes during fermentation. Some of the originally small scale, traditional SSF processes have become large-scale industries; it should therefore be worthwhile to study those factors that are conducive for large-scale production. In the future, SSF may become more important as a technology to process alternative, bio-based feedstocks that will replace the declining petroleum resources. There will be efforts and ever-increasing pressure to move towards biorefineries for the production of industrial biochemicals. ${ }^{4}$ The large-scale cultivation of microorganisms will be an integral part of such biorefineries. This can be achieved since SSF technology offers the advantage and potential to minimise the addition of water and thus optimise process economics in biorefineries. On top of that, in order to meet the requirements of SSF as a potential technology, it is necessary to produce effective large-scale SSF bioreactors with optimised performance.

\section{Definition of solid state fermentation}

SSF has been defined in many ways. Many researchers in the field have introduced their own ways to define SSF. For example, Pandey et al. ${ }^{5}$ defined SSF as the cultivation of microorganisms on moist solid supports, either on inert carriers or on insoluble substrates that can also be used as carbon and energy source. Mitchell et al. ${ }^{6}$ described SSF as any process in which substrates in a solid particulate state are utilised, while Viniegra-Gonzàlez ${ }^{7}$ defined SSF as a microbial process 
occurring mostly on the surface of solid materials that have the property to absorb or contain water, with or without soluble nutrients. Rahardjo et al. ${ }^{8}$ in their review article, came out with a definition that SSF is the growth of microorganisms on moistened solid substrate, in which enough moisture is present to maintain microbial growth and metabolism, but where there is no free-moving water and air is the continuous phase. Rosales et al. ${ }^{9}$ gave a simple definition of SSF where the growth of microorganisms is on solid or semisolid substrates or support.

Table I Development of SSF products ${ }^{2}$

\begin{tabular}{ll}
\hline Time & Products \\
\hline 2000 BC & Bread making by Egyptians \\
1000 BC & Cheese making using Penicillium roqueforti \\
550 BC & Sauce, koji \\
$7^{\text {th }}$ century & Kojic acid \\
$16^{\text {th }}$ century & Kojic acid was introduced to Japan \\
$18^{\text {th }}$ century & Fermented tea \\
$1860-1900$ & Vinegar from pomace, gallic acid in tanning, printing \\
$1900-1920$ & Sewage treatment \\
$1920-1940$ & Production of fungal enzymes, microbial enzymes, kojic acid \\
$1940-1950$ & Development of pneumatic drum-type fermenter \\
$1950-1960$ & Production of gluconic acid, citric acid \\
$1960-1980$ & Development of drum-type fermenter \\
& Premendous development in fermentation industry \\
& Steroid transformation \\
\hline
\end{tabular}

Bioprocess: Bioremediation, biodegradation of hazardous materials, biological detoxification of agro-industrial wastes, biotransformation of crops and crop residues for nutritional enrichment, biopulping, etc.

Products: Bioactive compounds:Aflatoxin, ochratoxin, bacterial endotoxins, gibberellic acid, zearalenone, ergot alkaloids, penicillin, cephalosporin, cephamycin C, tetracycline, chlorotetracycline, oxytetracycline, iturin, actinorhodin, methylenomycinn, surfactin, monorden, cyclosporine A, ustiloxins, antifungal volatiles, destrucxins A \& B, clavulonic acid, mycophenolic acid

$1990-2000$

Enzymes: Various enzymes (cellulase, $\beta$-glucosidase, CMCase, laccase, xylanase, polygalacturonase, ligninase, $\beta$-xylosidase, a-arabinofuronosidase, Li-peroxidase, Mn-peroxidase, aryl-alcoholoxidase, catalase, phenol oxidase, proteases (acidic, neutral and alkaline), lipases, $\alpha$-galactosidase, $\beta$-galactosidase, $\alpha$-amylase, $\beta$-amylase, glucoamylase, glutaminase, inulinase, phytase, tannase, feruloyl para-coumaroyl esterase, etc.)

Organic acids: Citric acid, fumaric acid, lactic acid, oxalic acid, gallic acid

Other products: L-glutamic acid, pigments, carotenoid, xanthan gum, succinoglycan, ethanol, aroma compounds, vitamins B-I 2 and B-6, riboflavin, thiamine, nicotinic acid, nicotinamide, gamma-linolenic acid, biosurfactants, biopesticides/bioherbicides

2000-present SSF as a novel process to generate feedstock for biorefinery processes

Future $\quad$ Move toward biorefineries for the production of industrial biochemicals

Later, Mitchell et al. ${ }^{4}$ defined SSF as a process that involves the growth of microorganisms on moist particles of solid materials in beds in which the spaces between the particles are filled with a continuous gas phase. Thomas et al. ${ }^{10}$ defined SSF as a three-phase, heterogeneous process, comprising solid, liquid and gaseous phases, which offers potential benefits for the microbial cultivation for bioprocess and products development. In the latest definition, Ashok et al. ${ }^{11}$ defined SSF as a process involves cultivation of microorganism on solid substrate with minimal moisture content. Whatever the definition, we can understand that SSF is referring to the microbial fermentation, which takes place in the absence or near absence of free water, thus being close to the natural environment to which the selected microorganisms, especially fungi, are naturally adapted. 


\section{Perceived advantages of SSF}

Claims of many advantages of SSF have been made compared to SMF in the literature. The question is; are these advantages real? Is it true that SSF is so much better than SMF? Maybe some claims are true, but many are still doubtful and need further proof. Indeed, SSF has centuries of history, but it is only in the last two decades that there has been a concerted effort to understand bioprocessing aspects involved in SSF and to apply them to a wide range of new products. ${ }^{12,13}$ Although significant advances have been achieved in understanding the controls of process performance, much research is still required. Studies on SSF and some of their results have provided a substantial contribution to the improvement of the existing and widely used technology. To a certain extent, some of the research findings have widened the scope of research activities towards a better understanding of existing SSF systems. The various advantages that have been identified through the literature can be described based on

Table 2 The perceived advantages of SSF different criteria, namely

i. Biological advantages

ii. Processing advantages

iii. Environmental advantages and

iv. Economic advantage

Table 2 shows the main advantages of SSF listed and summarised within these four categories. SSF has emerged as a viable technology for the bioremediation and biodegradation of hazardous compounds as well as the recycling of food and agro-industry wastes and biomass conservation. Moreover, SSF is a promising technology and is reliable for the development of various biotechnological products. Arguably, these advantages may in some circumstances outweigh the disadvantages of SSF that are discussed in the next section.

\begin{tabular}{|c|c|}
\hline Type of advantage & Remarks \\
\hline \multirow{12}{*}{ Biological } & Biological advantages that have been demonstrated in enzymes production \\
\hline & Products produced in high volume \\
\hline & Higher productivity level of the products \\
\hline & Higher stability of products \\
\hline & Absence of catabolic repression \\
\hline & Tolerance to high substrate concentration \\
\hline & Other biological advantages \\
\hline & Natural, complex raw materials often provide a complete medium \\
\hline & Absence of rigorous control of fermentation process \\
\hline & Easier aeration \\
\hline & Low water demand helps to minimise contamination \\
\hline & $\begin{array}{l}\text { Practically involves fungi-producing spores. Spores can be used as inoculum, can be preserved for a long time and } \\
\text { can be used repeatedly }\end{array}$ \\
\hline \multirow{10}{*}{ Processing } & Absence of production of foam \\
\hline & Processing advantage that have been demonstrated in enzymes production \\
\hline & Bioreactors are usually in small volume and are compact \\
\hline & The volume of the substrate loading is much higher \\
\hline & Other processing advantages \\
\hline & The growth substrates are from natural resources proportionally simple and unrefined \\
\hline & Pre-treatment and treatment of the natural resources can be very simple \\
\hline & Downstream processing might be simple since products are concentrated \\
\hline & Extraction of the products requires much less solvent (if necessary) \\
\hline & The process does not involve anti-foam chemicals \\
\hline \multirow{3}{*}{ Environmental } & Minimise the generation of pollutants or harmful waste during products manufacture \\
\hline & Produce less liquid waste \\
\hline & Solving waste problem as biological detoxification \\
\hline \multirow{4}{*}{ Economic } & $\begin{array}{l}\text { Substrates usually natural materials - Natural unusable carbon source which are extremely cheap, variable and } \\
\text { abundant agro-industry and food waste }\end{array}$ \\
\hline & Modified bioreactors are simple, cheap and user-friendly \\
\hline & Low recovery cost in downstream processing \\
\hline & SSF process is very attractive from an economic point of view and proved to be economically feasible \\
\hline
\end{tabular}




\section{Disadvantages of SSF}

Even though SSF offers certain unique advantages, it also suffers from some problematic disadvantages. Scientific studies that have been carried out in laboratories have helped to understand the chemical and microbiological changes that occur during the fermentation process. As we know from traditional technology for processing fermented food to produce valuable biotechnology products, SSF has a tremendous potential for industrial exploitation. In some cases, it is true that SSF has problems with scaling up but the process has been shown advantageous in competition with SMF. Research is needed to increase the capability of SSF for the development of biotechnological products. Being the aim of this study, one of the targets of this research activity is to explore any factors contributing to the disadvantages of SSF. Since such factors are not fully understood and not well reported, the fermentation strategy is based more or less on biomass and enzymes production combined with empirical studies. Some of the biological disadvantages in SSF have been defined and are summarised in Table 3. In this regard, having an understanding of growth characteristics is necessary. Moreover, such an understanding is important for rational design and process control in SSF. It should be worthwhile to study those factors conducive for understanding and improvement of the SSF process.

Table 3 The disadvantages of SSF

\begin{tabular}{|c|c|c|}
\hline No & Solid state fermentation disadvantage & Idea to overcome \\
\hline I & $\begin{array}{l}\text { Engineering problems due to the build-up of temperature, } \mathrm{pH} \text { control, } \\
\text { oxygen transfer, mass and heat transfer, substrate and moisture gradients } \\
\text { Uneven distribution of the cell mass, nutrients, temperature, } \mathrm{pH} \text {, moisture } \\
\text { content }\end{array}$ & $\begin{array}{l}\text { Measure build-up of temperature, oxygen and carbon } \\
\text { dioxide gradients on-line and use these to control the } \\
\text { system }\end{array}$ \\
\hline 3 & Steady aeration throughout the substrate is difficult & $\begin{array}{l}\text { Controlled by forced aeration. At the same time, this can } \\
\text { control the temperature }\end{array}$ \\
\hline 4 & $\begin{array}{l}\text { Heat derived from metabolism and growth of the microorganism raises the } \\
\text { temperature of the solid substrate and causes either loss of moisture or } \\
\text { generation of watery substrate }\end{array}$ & $\begin{array}{l}\text { Building temperature gradients capable of removing } \\
\text { metabolic heat }\end{array}$ \\
\hline 5 & Biomass measurement for microbial growth & $\begin{array}{l}\text { Development of on-line measurements and use these to } \\
\text { control the system }\end{array}$ \\
\hline 6 & $\begin{array}{l}\text { Growth and kinetics studies still difficult; even though information is } \\
\text { variable, it is still relatively limited and scattered }\end{array}$ & $\begin{array}{l}\text { Mathematical models for effective prediction and } \\
\text { optimisation of data }\end{array}$ \\
\hline
\end{tabular}

\section{The difference between SSF and SMF}

In contrast to SSF, the typical SMF is $100 \%$ liquid with, possibly, some suspended solids. The moisture content of SSF, on the other hand, is usually maintained in the range of $12-70 \%$, and typically around $60 \%{ }^{2}$ SMF is by far the most common operation employed in the fermentation industry. ${ }^{14}$ Most research in SMF is aimed at determining the production economics of the process including productivity and product yields ${ }^{15}$ and maximising these parameters. The use of filamentous fungi for the production of commercially important products has increased rapidly over the past half-century and the production of enzymes in SMF has long been established. ${ }^{16}$ SMF currently produces commercial enzymes and several of the potential applications have been commercially exploited, primarily due to shortage and high cost of enzymes. ${ }^{17}$ Advantages of SMF include good control of environmental parameters, relatively low labour costs, reduced space requirements and low scale-up requirements when compared with SSF. ${ }^{18}$

Even though modern SMF offers many advantages, it suffers from some major disadvantages. Soares et al. ${ }^{19}$ reported that SMF for transglutaminase production showed some constraints such as a long fermentation process, excessive foam production that prevented optimum oxygen mass transfer and use of expensive culture media. Some of these difficulties arise when fermentation involves the use of filamentous fungi. Professor APJ Trinci used the now frequently quoted phrase "God did not create filamentous fungi to grow in a fermenter. ${ }^{12}$ " He claimed that SMF is an artificial condition for filamentous fungi because they live in nature in a solid state. ${ }^{12}$ Most microorganisms, especially filamentous fungi and many actinomycetes, primarily live and grow in nature in SSF conditions. ${ }^{20}$ More than $98 \%$ of isolates from marine environment have been obtained from the underwater surfaces of solid substrates and less than $1 \%$ of all known fungi have been found in marine habitats. ${ }^{21}$ The morphology factor of the microorganisms plays an important role since it can affect many aspects of the process. Table 4 emphasises the major differences in characteristics between SSF and SMF. ${ }^{2}$

\section{Factors that influence SSF}

SSF processes are clearly different from SMF. In most cases, it is soluble substrate supported on a solid insoluble matrix in an environment of low moisture content. The advantage of SSF comes from its simplicity and its closeness to the natural habitat of many microorganisms. Through modern biotechnology, there are new initiatives to improve and enhance the productivity of SSF. Each microorganisms, solid substrate, and bioreactor system plays a major role in the success of SSF. The performance of the SSF process can be influenced by various factors. Broadly, the factors that influence the performance of SSF can be divided into three major categories, namely
i. Biological factors
ii. Physico-chemical factors and
iii. Mechanical factors 
Table 4 Detailed comparison of SSF and SMF²,22,23

\begin{tabular}{|c|c|}
\hline SSF & SMF \\
\hline $\begin{array}{l}\text { There is no free water, and the water content of substrate is in the range } \\
12-70 \%\end{array}$ & Water is the main component of the culture \\
\hline $\begin{array}{l}\text { Microorganisms absorb nutrients from the wet solid substrates; a nutrient } \\
\text { concentration gradient exists }\end{array}$ & $\begin{array}{l}\text { Microorganisms absorb nutrients from the liquid culture; there is } \\
\text { no nutrient concentration gradient }\end{array}$ \\
\hline $\begin{array}{l}\text { The culture system consists of three phases (gas, liquid and solid) and gas is } \\
\text { the continuous phase }\end{array}$ & $\begin{array}{l}\text { The culture system mainly consists of liquid; the liquid is the } \\
\text { continuous phase }\end{array}$ \\
\hline Inoculation size is large, more than $10 \%$ & Inoculation size is small, less than $10 \%$ \\
\hline $\begin{array}{l}\text { The required oxygen is from the gas phase; the process needs low energy } \\
\text { consumption }\end{array}$ & $\begin{array}{l}\text { The required oxygen is from dissolved oxygen; there is a larger } \\
\text { amount of dissolved oxygen }\end{array}$ \\
\hline Microorganisms attach and penetrate into the solid substrate & Microorganisms uniformly distribute in the culture system \\
\hline $\begin{array}{l}\text { At the end of fermentation, the medium is a wet state substrate, and the } \\
\text { concentrations of products are high }\end{array}$ & $\begin{array}{l}\text { At the end of the fermentation, the medium is liquid and the } \\
\text { concentrations of products are low }\end{array}$ \\
\hline High production rate and high product yield & Low production rate and low product yield \\
\hline $\begin{array}{l}\text { Mixing is difficult or impossible, some microorganisms are sensitive to } \\
\text { mixing or agitation and the growth of microorganisms is restricted by } \\
\text { nutrient diffusion }\end{array}$ & $\begin{array}{l}\text { Mixing is easy, and the growth of microorganisms is not restricted } \\
\text { by nutrient diffusion }\end{array}$ \\
\hline Removal of metabolic heat is difficult & Temperature control is easy \\
\hline Heterogeneity & Homogeneity \\
\hline The fermentation parameters are hard to detect and control on-line & $\begin{array}{l}\text { The fermentation parameters can be detected and controlled } \\
\text { on-line }\end{array}$ \\
\hline Extraction process is simple and controllable; little waste water & $\begin{array}{l}\text { Extraction process is usually complex; there is a large amount of } \\
\text { waste water }\end{array}$ \\
\hline Low water activity & High water activity \\
\hline Simple fermentation bioreactor & High-tech design fermentation bioreactor \\
\hline Natural enrichment or artificial breeding systems & Pure strains \\
\hline Energy consumption and equipment investment are high & Energy consumption and equipment investment are low \\
\hline Low raw material cost & High raw material cost \\
\hline
\end{tabular}

\section{Biological factors}

The type of microorganism: The most important criterion in SSF is the selection of a suitable microorganism, which has the ability to degrade the solid substrate. SSF processes are due mainly to the fermentation activity of fungi alone, bacteria alone, a mixture of fungi and yeasts or fungi followed by a mixture of bacteria and yeast. The selection of microorganism is usually dependent on the type of solid substrate, growth requirements and targeted final product. ${ }^{1}$ These general criteria will affect the fermentation design and downstream processing. Filamentous fungi continue to dominate as an important microorganism in SSF due to their mycelia mode of growth as well as their neutral physiological capabilities. ${ }^{4}$ The use of a single microorganism, especially in industrial SSF processes, has the advantage of improved rate of substrate utilisation and controlled product formation. ${ }^{22}$ Ensiling and composting are among the processes involving several microorganisms that exhibit symbiotic behaviour; in other words, mutual growth of microbial communities and thus mixed culture processes, as these exist in most natural habitats. ${ }^{22}$
Inoculum: Inoculum can be described as a preparation containing high numbers of viable microorganisms, which may be added to bring about desirable changes in the solid substrate. ${ }^{24}$ The age of the inoculum, the medium used for its cultivation, and therefore its physiological state are of the utmost importance in many fermentation processes. ${ }^{25}$ According to Crafack et al. ${ }^{26}$ if the inoculum used for the production of secondary metabolites is not in the correct physiological state, a considerable decrease in production will occur. This is because the early hours of fermentation determine the future direction of the culture. Sekiguchi et al. ${ }^{27}$ observed that with Penicillium urticae the type of inoculum used greatly influences the level of secondary metabolites produced. Smith et al..$^{28}$ reported that different yields were obtained in penicillin and griseofulvin fermentation using different types of inoculum. From their study, it was shown that biochemical factors, such as the level of enzyme activity and efficiency, were at least as important as morphology in determining yield, being carried forward from the inoculum to the production stage. For example, most fungi produce spores. Spores inocula are easy to prepare and can be stored for longer periods than vegetative cells. The chances for con- 
tamination are higher if low levels of inoculum density were used. According to Nigam et al., ${ }^{29}$ by increasing the inoculum quantity, the time required for substrate utilisation can be shortened and this can also aid the inoculated fungus to displace any other microbes that may be present. This makes processes involving fungi more flexible since the synchronisation of inoculum production with the rest of the process is not that crucial. Sporulation is generally not desirable during the fermentation itself. ${ }^{30}$

Substrates: Carbon sources supplied in the medium are of great importance to fungi since they provide the carbon source needed for the biosynthesis of cellular constituents. ${ }^{31}$ This includes carbohydrates, proteins, lipids, nucleic acids, and their oxidation provides energy for the cell. The solid substrate is a major element in SSF. In addition to providing nutrients such as carbon and nitrogen, the solid substrate also performs the role of the physical structure that supports the growth of microorganisms. ${ }^{32}$ Another important factor in the selection of substrate is the water holding capacity that maintains moisture content of the fermented substrate..$^{22}$ Generally, most of the solid substrates used in SSF are based on food and agro-industry crops and residues..$^{33}$ They are usually unprocessed and come with different particle sizes. ${ }^{1}$ The quality and nutrients composition of the solid substrate might be different from one batch to another. This can lead to problems with heterogeneity and overall productivity of the fermentation process. Generally, solid substrates used in SSF can be classified into five main groups, namely:

Starchy substrates: Starchy substrates that have been used in SSF include rice, barley, oats, cassava, wheat bran, cassava meal, corn meal, okara, sweet potato residues, and banana peel. Starchy substrates, being rich in carbohydrates (important carbon source in many microbial fermentation processes), are hydrolysed to produce simple sugars that can be consumed easily by microorganisms.

Substrates with protein: Food and agro-industry by-products such as oil cakes are an ideal source of proteinaceous nutrients. Their use as a solid substrate is highly favoured in SSF. Pumpkin oil cake $(63.52 \%),{ }^{34}$ soybean oil cake $(51.8 \%),{ }^{35}$ sesame oil cake $(48.2 \%),{ }^{36,37}$ groundnut oil cake $(45.6 \%),{ }^{37,38}$ safflower oil cake $(44.0 \%),{ }^{39}$ rapeseed meal oil cake $(42.8 \%),{ }^{40}$ cottonseed oil cake $(41.0 \%),{ }^{41}$ mustard oil cake $(38.5 \%)$, sesame oil cake $(35.6 \%)$, sunflower oil cake $(34.1 \%)$ and canola oil cake $(33.9 \%){ }^{42}$ linseed oil cake $(32-36 \%),{ }^{43}$ coconut oil cake $(25.2 \%),{ }^{37,44}$ copra oil cake $(23.11 \%)$ and palm kernel oil cake $(20.4 \%)^{45}$ and olive oil cake $(4.77 \%)^{46}$ are the most abundant agriculture by-products. Oil cakes, being rich in proteins (important nitrogen source in many microbial fermentation) and supported by other nutrients such as carbohydrates and minerals, offer a wide range of alternative substrates in SSF for the production of various enzymes (for example proteases, lipases etc), a wide spectrum of secondary metabolites, biomass, organic acids and biofertilizer among other uses.

Cellulosic or lignocellulosic substrates: Most agricultural residues contain high levels of cellulose or lignocellulose, which have the potential to be used as solid substrates in SSF. These include sugarcane bagasse, soybean hulls, wheat bran, rice hulls, rice stover, corn cob, barley husk, sugar beet pulp, wheat straw, barley straw and wood. In this case, cellulolytic fungi such as Trichoderma, ${ }^{47}$ Trichoderma, ${ }^{48}$ Trichoderma viride, ${ }^{49}$ Aspergillus niger, ${ }^{50}$ Clostridium cellulolyticum,$^{51}$ Rhizopus sp. ${ }^{52}$ Streptomyces $\mathrm{sp} .{ }^{53}$ and ligninolytic fungi such as white-rot fungi ${ }^{54-57}$ are able to degrade complex cellulose and lignocellulose to produce simple sugars.

Substrates with soluble sugars: Solid substrates containing signifi- cant amount of soluble sugars may be obtained from fruit processing such as molasses, grape pomace, apple pomace, kiwi pomace, lemon peel, lemon pulp, peach pomace, pineapple waste, sweet sorghum, fodder and sugar beets, sugar beet pulp, carob pods, and coffee pulp.

Defined media and inert carrier: There are various inert carriers that can be used to simulate the conditions of typical SSF. These include vermiculite, perlite, clay granules, pozzolano particles (volcanic material), hemp, amberlite, polyurethane foam (PUF) and polystyrene. The inert carrier is filled with chemically defined liquid media. The advantages of SSF on inert support in comparison to SSF on natural solid substrates ${ }^{58-63}$ include:

i. Enhancing the homogeneous aerobic conditions

ii. Improving process control and monitoring

iii. the inert carrier has less physical structure changes or can even be constant during fermentation

iv. Improved control of heat and mass transfer

v. Higher evaporation rates and thus better control of temperature

vi. Good control of water activity

vii. Shrinkage and channelling are avoidable

viii. Less complicated and easy product recovery

ix. Easy to extract extracellular products with fewer impurities

$\mathrm{x}$. The inert carrier allows precise modification of production liquid media

xi. Easy and possible process modelling and process control because the production media are known and can be analysed

xii. Biomass can be measured directly

xiii. Suitable to grow any microorganism based on defined media and

xiv. The inert carrier can be reused

Some natural solid substrates such as sugarcane bagasse and rice hulls can be used as inert carrier due to their low nutrients but high porosity and ability to provide a very good support in terms of controlling mass and heat transfer. ${ }^{64}$ Sugarcane bagasse provided enough area for vegetative hyphae of Verticillium lecanii to attach while aerial mycelium freely penetrate into the internal are of polyurethane foam. ${ }^{52,61}$

\section{Physico-chemical factors}

Moisture content: The water requirements of microorganisms for microbial activity can be expressed quantitatively in the form of water activity $\left(a_{w}\right)$ of the environment or substrate. The $a_{w}$ gives an indication of the amount of free water in the substrate and determines the type of microorganisms that can grow in SSF. The required $a_{w}$ value for SSF varies depending on the microorganism, but it is usually recommended that the $\mathrm{a}_{\mathrm{w}}$ be enough to permit growth of mycelium through the solid substrate particles without disintegrating the particles ${ }^{65}$ According to Nigam et al. ${ }^{29}$ microorganisms capable of carrying out their microbial activities at lower $\mathrm{a}_{\mathrm{w}}$ values are suitable for SSF process. Bacteria mainly grow at higher $\mathrm{a}_{\mathrm{w}}$ values of about 0.9 , while yeasts grow at values of 0.8 and filamentous fungi are adaptable to lower $a_{w}$ values ranging between 0.6 and 0.7..$^{29,66}$ However, according to Ruijiter et al., ${ }^{67}$ the fungus $A$. oryzae accumulates high concentrations 
of polyols at water activities between 0.96-0.97 during SSF, which seems to be unusual for this type of processing. As the fermentation starts at low moisture content, the culture dries out. Consequently, the fungus grows poorly and growth does not occur before the fermentation is completed. To overcome this problem, an appropriate amount of water is occasionally added throughout the fermentation period. ${ }^{68}$

Another approach is to apply saturated air. Saturated air is usually applied to the system as an alternative to maintain $\mathrm{a}_{\mathrm{w}}$ and moisture content of the fermented substrate. It is also a common practice used to avoid substrate drying. This approach is suitable when the SSF is carried out in designated bioreactors. At high moisture content, solid substrate particles tend to stick together and thus reduce the surface to volume ratio of solid material. According to Mitchell et al., ${ }^{30,69}$ high moisture levels can cause agglomeration of medium particles in SSF and lead to oxygen transfer limitations. As a result, a great decrease is observed in the production of microbial metabolites. Hence, it is important to provide and monitor the moisture content at an optimum level.

pH: In SSF, pH is very difficult to measure and control. This is because of the nature of solid substrate, very low water content (lack of free water), heterogeneity in the conditions of the systems, and due to the lack (or absence) of suitable on-line $\mathrm{pH}$ measurement methods. ${ }^{70}$ To the best our knowledge, there is no reliable electrode that can measure $\mathrm{pH}$ in the solid medium. Usually it is desirable to use microorganisms which will grow over a wide range of $\mathrm{pH}$ and which have broad $\mathrm{pH}$ minima. ${ }^{71}$ Individual groups of microorganisms react in different ways to the $\mathrm{pH}$ value of the fermentation environment Bacteria generally prefer $\mathrm{pH}$ values near neutrality, fungus and yeast slightly acid $\mathrm{pH}$ values, and actinomycetes above neutrality. Villegas et al. ${ }^{72}$ suggested using of a potentiometric electrode or a standard $\mathrm{pH}$ electrode after suspending the fermented substrate in water.

Temperature: The problem regarding temperature arises during the SSF process due to the heat generated from microbial activity and accumulated in the system. ${ }^{22}$ Temperature due to heat and mass transfer effects present's difficulties in handling the SSF process. ${ }^{1}$ The heat needs to be removed from the system to avoid overheating and thereby disturbing the growth of microorganisms and the formation of products. ${ }^{73}$ Therefore, in SSF, most studies on solid state bioreactor designs are focused on maximising heat removal. ${ }^{74,75}$ The problem becomes crucial in large-scale systems where heat evolution leads to huge moisture losses and, under these circumstances, disturbing fungal growth. ${ }^{76,77}$ Another problem is that heat creates condensation such that a large amount of water is returned back to the fermented solid. This will create heterogeneity in the solid substrate. Because of this, it is difficult to maintain the temperature at an ideal range. To overcome this, air is usually blown into the system, to force out the heat generated via a gas outlet. ${ }^{78}$ The flow rate of the air blown into the system needs to be taken into account to avoid the loss of moisture content from the fermented substrate. ${ }^{79}$ A cooling system can also be installed into the system to solve this problem.

Gaseous environment: The gases of interest are oxygen and carbon dioxide. Oxygen must diffuse from the inter-particle space to the biomass. Adequate supply of oxygen is required to maintain aerobic conditions. Carbon dioxide must diffuse from the biomass to the inter-particle space and must be removed from the system. This requirement can be achieved by aeration or mixing of the fermenting solids. Oxygen limitation might occur at deep areas of the substrate. This situation can be overcome by turning the fermenting substrate through mixing processes. ${ }^{75,80,81}$
Aeration: Microorganisms normally vary in their oxygen requirements. Oxygen or air is sparged into the medium. Aeration plays two important roles in SSF:

\section{i. Meeting the oxygen demand in aerobic fermentation and \\ ii. Heat and mass transport in a heterogeneous system}

Aeration provides and maintains high oxygen levels and low carbon dioxide levels in the inter-particle solid substrates. The points to take into account with the aeration are the flow rate and air quality. Dry air at high flow rate will have an effect on the moisture of fermented substrate even though it has an advantage in terms of heat removal. Aeration rate was shown to have a positive effect on microbial growth and product formation. ${ }^{82-84}$ Alternatively, using saturated air is a common strategy to avoid substrate drying by maintaining moisture levels. In addition, the rate of aeration by saturated air controls the temperature and the moisture gradients of the solid medium. ${ }^{85}$

Particle size: The particle size properties of solid substrates will lead to the shape, accessible area, surface area and porosity of the solid substrates. ${ }^{86}$ Processes like chopping, grinding and cutting create a condition for microorganisms to be active at the initial stages of growth and increase the degradation and hydrolysis rate since the solid substrate is insoluble. ${ }^{87}$ The most important physical factor is the particle size that affects the surface area to volume ratio of the solid substrate. ${ }^{1}$ Smaller particle size would provide a larger surface area per volume and allow full contact of microorganisms with the nutrients but the diffusion of oxygen would be affected..$^{22}$ Larger particle size provides small area per volume ratio and gives excellent diffusion of oxygen but contact with nutrients is affected ${ }^{88}$ A suitable particle size should satisfy both mycelial growth and the demand for oxygen and nutrients. ${ }^{89}$ Particle size also affects the size of inter-particle voids and porosity. ${ }^{30,69}$ Any change in porosity of the solid substrate bed changes the apparent density of solid substrate and diffusion of gases into the bed. A large pore size is suitable for an adequate oxygen supply..$^{90}$ If porosity is limited, the effective diffusivity of gases is less. Particle size and properties may change during fermentation. These do not only affect the growth of microorganisms, but also affect the monitoring of heat conductivity, substrate consumption, products concentration and water content. ${ }^{91}$

\section{Mechanical factors}

Agitation/Mixing: Agitation or mixing plays the same role as aeration. In addition, agitation is a possible alternative to solve heterogeneity problems in SSF and might improve homogeneity and disrupt gradients. ${ }^{80,81,92}$ Another benefit of agitation is that airflow is more evenly distributed which improves the conditions for microbial growth within the entire fermented bed..$^{93}$ However, agitation affects mycelium formation as shear forces due to agitation can destroy the mycelium. Continuous agitation also may create problems related to cell damage especially when filamentous fungi are used. ${ }^{4,94}$ A slower agitation speed might be necessary and some bioreactors perform this by using intermittent agitation to avoid serious damage to the mycelium. ${ }^{95}$ Agitation within an SSF process is preferred with bacteria or yeast as their cells are usually not in tight contact with the solid substrate surface. Overall, this agitation or mixing procedure is not always advisable.

Particular design of bioreactors: In the fermentation process, the bioreactor provides the suitable conditions for growth and activity for the microorganisms involved, which allow the microbiological activity. SSF can be considered to be a "closed system". At time $\mathrm{t}=0$, 
the sterilised solid substrate in the bioreactor is inoculated with the microorganism and incubation is allowed to proceed under optimal physiological conditions. In the course of the entire fermentation, nothing is added into the bioreactor except oxygen (in the form of air). The composition of the culture medium, the biomass concentration and the metabolites concentrations generally change constantly as a result of the metabolism of the cells. Despite the heterogeneity of the solid substrate in the bioreactor, there are several parameters such as transport of oxygen and metabolic heat which involves aeration/agitation, moisture content, temperature and the type of microorganism and solid substrate used, which are relevant to the particular design of the suitable bioreactor for each particular fermentation process. A detailed discussion will be provided in the next section on bioreactors for SSF.

\section{Bioreactors for SSF}

SSF bioreactor design greatly depends on the solid substrate. According to Musoni et al., ${ }^{96}$ the bioreactor is the core of biological process. There are four major roles of the bioreactor, which are:

i. To contain the substrate

ii. To contain the process microorganism

iii. To protect the process microorganism against contamination and

iv. To control environmental conditions to optimise growth and product formation.

In SSF or SMF processes, the bioreactor provides suitable environment for microorganism growth and biological activity. ${ }^{1}$ Bioreactors must be able to hold the media and be sealed well which prevents harmful environment substances entering in to bioreactor. Various types of bioreactor system have been developed and used in SSF processes. The most important benefit has been greater understanding of the biological system of the microorganism and biological processes in SSF. ${ }^{30}$ Research has found that temperature, $\mathrm{pH}$, oxygen, carbon dioxide and heat removal need to be controlled and optimised. ${ }^{11,96}$ According to Pandey et al. ${ }^{12,13}$ SSF bioreactor design should carefully consider design and operating variables, especially aeration transfer, temperature control (including cooling system), effective diffusion of oxygen in gas phase and coefficient for heat transfer through bioreactor wall. In SSF, oxygen transfer can often be inefficient in some designs. ${ }^{11,97}$ The problems are complicated, affecting the temperature and the water content of the solid medium, which both need to be, controlled tightly.98,99 Effective bioreactors have high biological reaction rates including growth performance, substrate consumption, product formation and by-products synthesis rates. ${ }^{96}$ It is very important to understand which criteria provide the best bioreactor performance, so that bioreactors can be designed effectively.

Table 5 shows how the SSF bioreactors can meet many fermentation objectives and the limitations that prevent them from solving all problems. In SSF, matching a specific bioreactor to a certain bioprocesses needs a balanced consideration of many factors. These include oxygen transfer, mixing/agitation, aeration, temperature control, moisture gradients, operational stability and reliability, scale-up and cost. Selected bioreactor must have features and mode of operation that will optimise results. Importantly, every selected bioreactor operation will increase the biological processes and factors involved. Mitchell et al. ${ }^{4}$ argue that one of the main issues of bioreactor design and operation is the need to remove enough metabolic heat waste. This is important to prevent temperature within the fermented bed from getting too high as this affects microbial growth and product formation. Heat removal must be effective. It depends on control and support systems and how these fit into the production system. Finally, other process needs and setbacks should also be considered.

Table 5 Strengths and weaknesses of small-scale SSF bioreactors

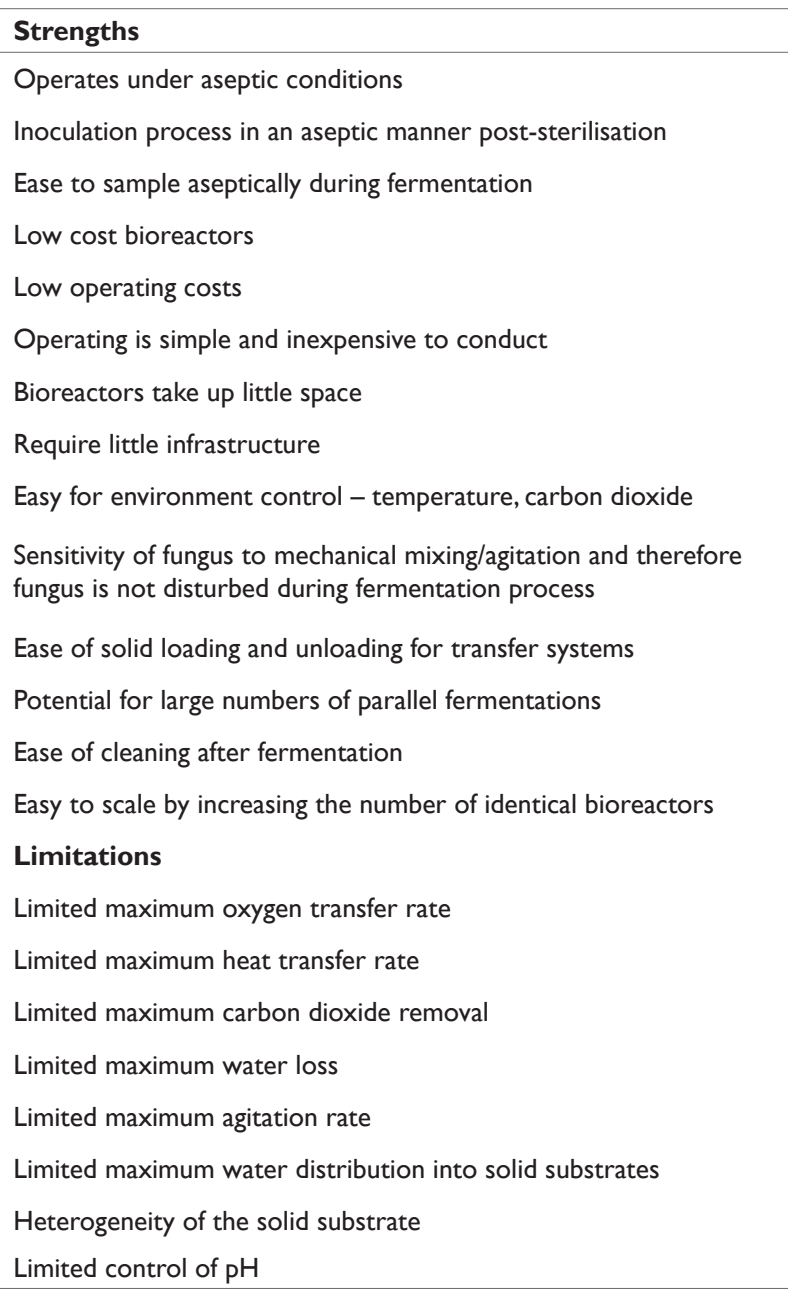

\section{Classification of bioreactors for SSF}

The main reason for designing SSF bioreactors is to address major problems such as transport of oxygen, removal of metabolic heat, moisture gradients and the heterogeneity of the solid substrate. According to Mitchell et al., ${ }^{98,99}$ good bioreactor performance is controlled by two factors:

i. The interactions between the microorganism and its local environment and

ii. Influence of the design and operating strategies on conditions in the microorganism's local environment.

Important parameters in bioreactor design include temperature, oxygen concentration, moisture gradients as well as mixing/agitation, aeration and heat transfer. Usually two strategies are used to produce excellent SSF processes, resulting in effective oxygen transfer, efficient heat removal, excellent water distribution and good substrate mixing with minimal mycelia damage. The two basic strategies of aeration and mixing are as follows: ${ }^{100,101}$ 
i. The air supply circulates around the fermented solid substrate particles and

ii. The air goes through the inter-particles of fermented solid substrate particles

Within strategy two, three mixing types can be used on the fermented beds: static (unmixed), intermittently mixing (agitated), or continuous mixing (agitated). For both strategies, dry air or saturated air can be used. According to Mitchell et al. ${ }^{100-101}$ SSF bioreactor designs can be classified into four groups (Figure 1), which can be separated by aeration and mixing type:

i. Group 1: unforced aeration, without mixing/agitation (static)

ii. Group 2: forced aeration, without mixing (static)

iii. Group 3: unforced aeration, with continuous or intermittent mixing/agitation and

iv. Group 4: forced aeration, with continuous or intermittent mixing/ agitation

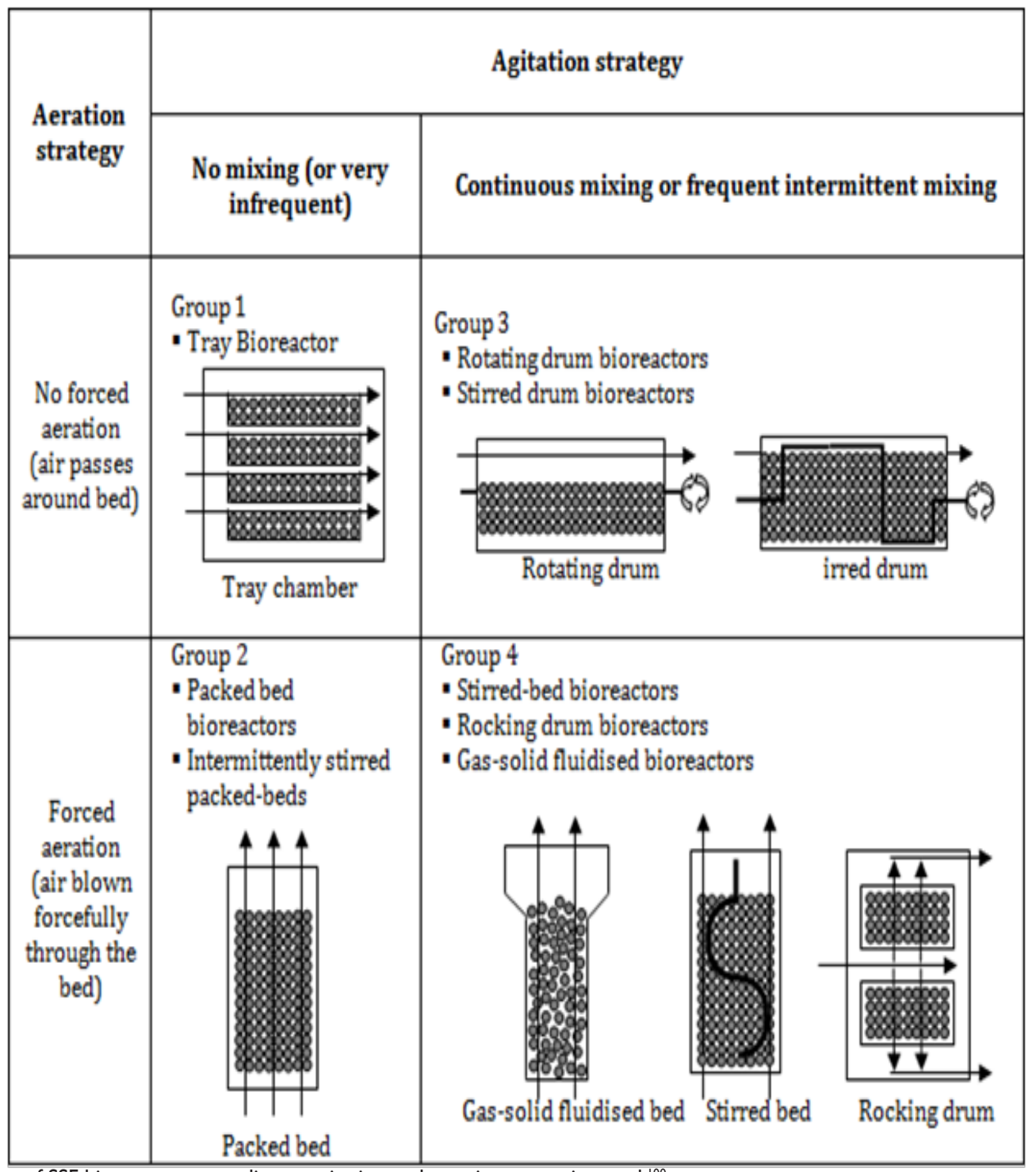

Figure I Classification of SSF bioreactors according to agitation and aeration strategies used. ${ }^{100}$

Mitchell et al. ${ }^{4}$ stated there are three main objectives of designing bioreactors:

i. To provide adequate heat removal

ii. To maintain adequate water activities and

iii. To provide high oxygen concentrations within the inter-particles spaces

Figure 1 from Mitchell et al. ${ }^{4}$ shows a typical SSF bioreactor and bioreactor phases (Figure $1 \& 2$ ). Figure $2 \mathrm{~A}$ gives an overview of the bioreactor system at the macro-scale, sometimes referred to as bioreactor vessel. At this scale, differences between solid substrate particles (fermented bed), headspace, and the wall of the body structure of the bioreactor are identified. Generally, from a macroscopic viewpoint, there are three main subsystems within SSF bioreactors:

i. A bioprocess takes place in the body structure of the bioreactor

ii. The fermented bed, which combines moist solid substrate particles and inter-solid substrate particles, which are filled with the oxygen and 
iii. The area on and above the surface of the fermented bed (known as the headspace), which has high oxygen concentration

Figure 2B gives the micro-scale overview of un-inoculated substrate. This can be known as solid phase. At this scale, moist solid substrate particles hold important nutrients and growth factors. Space between solid substrate particles known as void fraction, is filled with water and gas. Furthermore, the gradients of nutrients, oxygen and water will affect microbial growth. Figure $2 \mathrm{C}$ gives an overview of bacterial or yeast cultures growing and sticking to surfaces of the solid substrate particles, shown by the thick black layer at the particle surface. Figure 2D gives an overview of filamentous fungi growing by sticking to the surface and hyphae. Therefore, mycelium able to deeply penetrate into solid substrate particles to consume nutrients, oxygen, excreting metabolites and enzymes. At a small scale level, petri dishes and Erlenmeyer flasks can be used as laboratory scale bioreactors for SSF. Conditions are entirely aseptic, making this an advantage of using laboratory scale bioreactors. However, the disadvantage is that agitation and aeration cannot be carried out. Many industrial bioreactors have been designed. However, they have problems of sterilisation, substrate loading, heat generation, heat removal and handling difficulties.

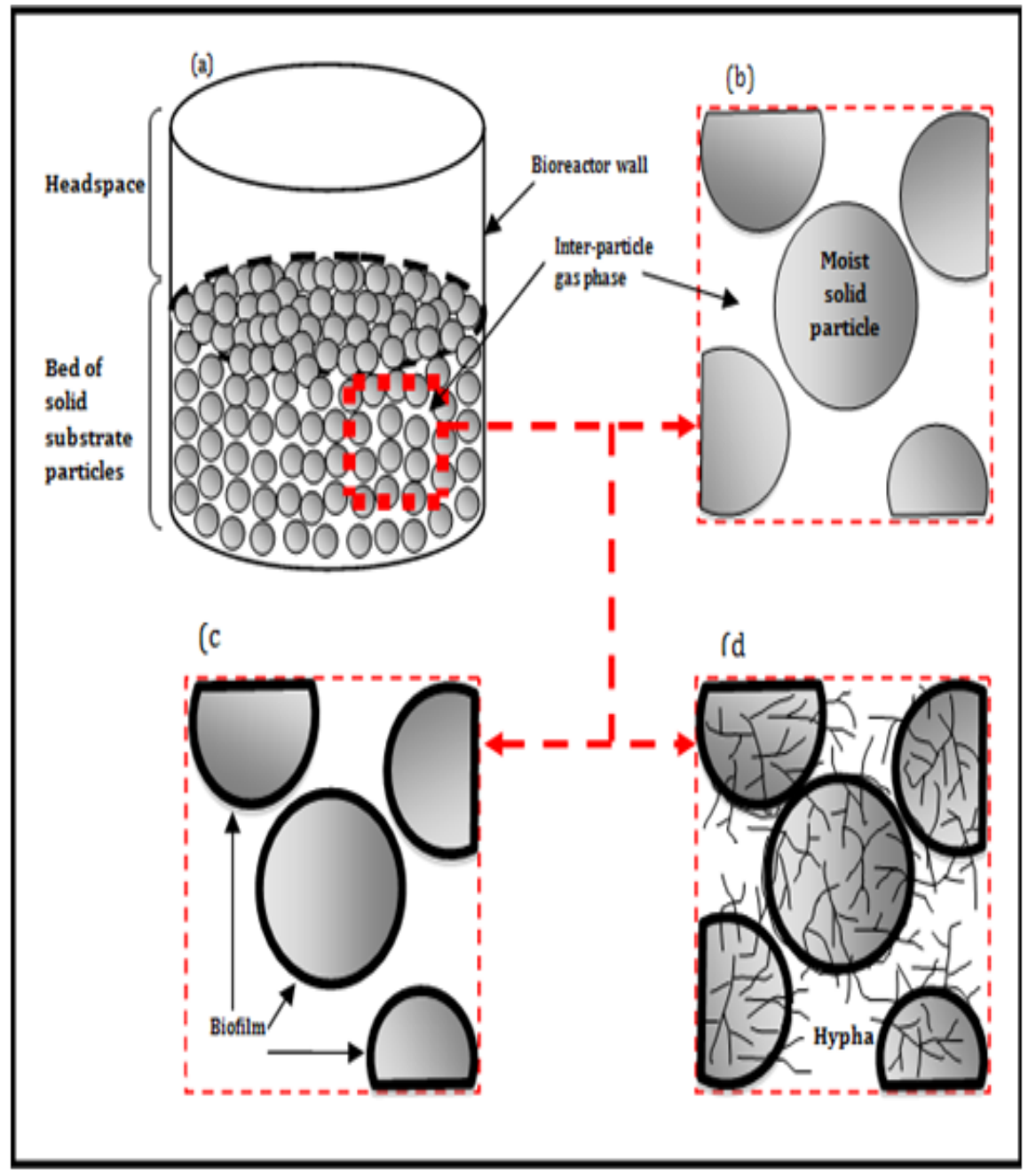

Figure 2 The phases within a SSF system. ${ }^{4}$

\section{Group I}

Tray bioreactors: Historically, tray bioreactors have been used widely in traditional SSF. Using trays is the oldest system and they are very simple in design and used in static conditions, unmixed beds with no forced aeration on the solid substrate. The fermentation is done in stationary trays with no mechanical agitation. The bottom of the tray is perforated with mesh to hold the solid substrate to allow a normal aeration. This system type only holds limited amount of solid substrate to be fermented. This is because only thin layers must be used, to avoid overheating from happening and to maintain aerobic conditions. ${ }^{102}$ Alcântara et al. ${ }^{103}$ and Vaseghi et al. ${ }^{104}$ found that substrate thickness; surface area and chamber temperature gave the positive effect on enzymes activity and could improve metabolic heat and gas transfer. ${ }^{105}$

Thickness of solid substrates bed can be varied. Usually trays are place in the incubating room, where temperature and humidity are controlled for optimal growth. Trays are arranged one above the other with suitable gaps between them. Tray design has not changed majorly. ${ }^{22}$ Zhang Chen et al. ${ }^{106}$ studied the effect of two dynamic changes of air (including air pressure pulsation and internal air circulating) in a tray bioreactor and observed changes in the temperature gradient. In their results, internal air circulation was beneficial, accelerating heat transfer between the substrate surface and the outside air. Furthermore, Ruiza et al. ${ }^{107}$ and Assamoi et al. ${ }^{82}$ designed column-tray bioreactors with forced aeration. This allowed better control of environmental conditions in the bed due to manipulation of temperature and flow rate of the air. Figure 3 shows general schematic multiple tray fermenters. 
Figure 3 Scheme of tray bioreactor. ${ }^{33}$

\section{Group 2}

Packed-bed bioreactors: Packed-beds bioreactors are built from glass or plastic columns and are made up of unmixed beds with perforated base. Forced aeration is applied to the bottom of the column. ${ }^{22}$ These systems are useful for product developments with efficient process controls, particularly for heat removal. ${ }^{99}$ Forced aeration using moistened air improves the moisture gradients of fermented bed and temperature control, compared with forced dry air. ${ }^{82}$ However, according to Gutiérrez-Rojas et al., ${ }^{108}$ not all the heat generated during fermentation process is eliminated. To achieve this, they suggested an injection of cool-dry air and replacing moisture at different points in the packed-bed. Salum et al. ${ }^{109}$ cultivated Burkholderia cepacia LTEB11 on a mixture of sugarcane bagasse and sunflower seed meal. They found that the fermentation solid could be used to catalyse the ethanolysis of soybean oil to produce biodiesel in a fixed packed-bed bioreactor (a co-solvent-free system). This strategy does not need expensive processing steps, for examples enzyme recuperation and immobilization and co-solvent separation. It is very effective and has potential to reduce the costs with enzyme-catalysed biodiesel synthesis. Figure 4 shows a general schematic packed-bed fermenter.

\section{Group 3}

Rotating drum bioreactors: Rotating drums bioreactors mix intermittently without forced aeration, operating on continuous or semi-continuous mode. A rotating drum bioreactor is a horizontal cylinder. The drum is semi-filled with a bed of substrate. The fermented bed cannot be too high and this creates good oxygen and carbon dioxide transfer. ${ }^{102}$ Nava et al. ${ }^{80}$ found even at small scale that temperature control in drum bioreactors is quite difficult. Solid substrate is mixed differently for different microorganisms. Mixing could be continuous, intermittent or mixed. This prevents metabolic heat generated by microbial activity accumulating. Temperature control also depends on the mixing effect on the solid substrate. ${ }^{110}$ Air also could be blown through the headspace. Also in forced aeration, conditioned air is passed through the bed. Metabolic heat is removed from the bed, transfers into headspace by diffusion or through the conductive wall to the environment. ${ }^{111}$ During intermittent mixing, growth of the microorganisms is found to be more even and less damaging to fungal mycelium..$^{98,112}$ Continuous mixing could increase damage to fungal mycelium, affecting microorganism growth. Stuart and Mitchell ${ }^{113}$ observed the operating variables of the rotating drum bioreactor when growing Aspergillus oryzae. They found that the growth rate decreased when rotational speed increased because of shear forces. Ali et al. ${ }^{111}$ suggest two possible ways to address these problems:

i. Intermittently mixing and aeration into the headspace. Both mixing and aeration could control the temperature, moisture gradients, uniformity and oxygen concentrations.

ii. Equipped with baffles on the inner wall.

Figure 5 shows a general schematic rotating drum bioreactor.

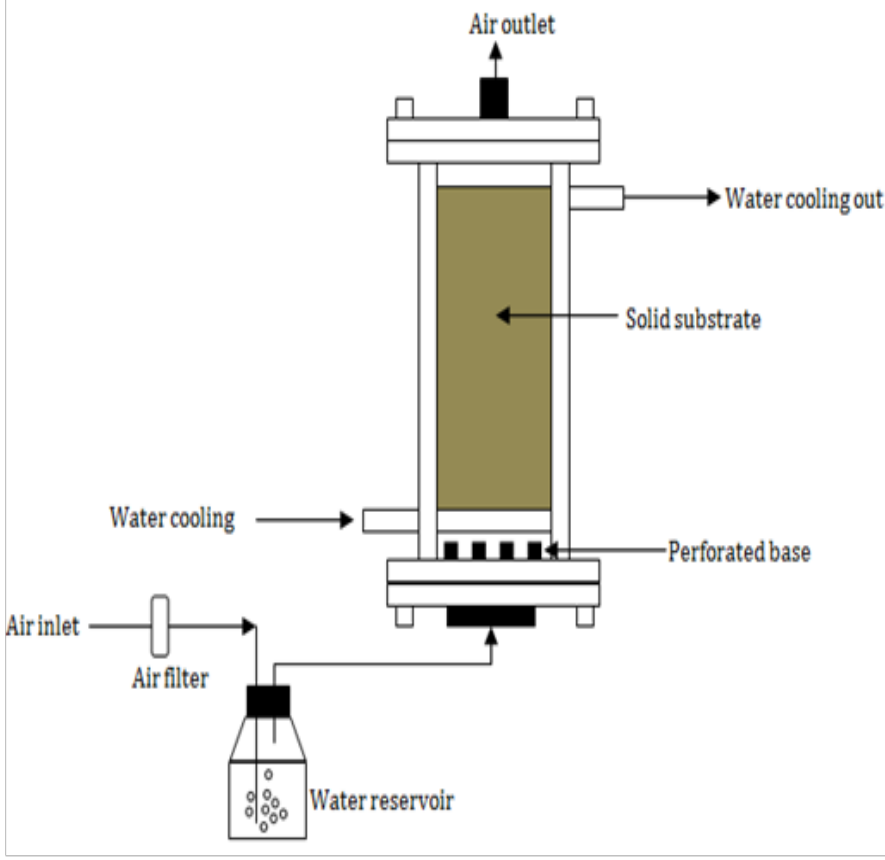

Figure 4 Scheme of a packed-bed bioreactor. ${ }^{33}$

\section{Group 4}

Fluidized-bed bioreactors: Typically, fluidized-bed bioreactors are constructed from a vertical chamber with a perforated base plate. Forced aeration is applied at the bottom chamber at sufficient speed to fluidize the solid substrate particles and cause mixing. Also, the bioreactor has an agitator (clump breaker), breaking up agglomerates that can form and settle to the bottom. ${ }^{114}$ The bed expands and 
so enough headspace is needed..$^{98}$ The mixture of solid particles and gas will behave like a liquid. This fluidized-bed bioreactor provides a good mixing behavior of gas, solid and liquids. ${ }^{23}$ Evaporating water can cool the biomass. ${ }^{115}$ The substrate properties of gas-solid fluidized-bed bioreactors influence bioreactor effectiveness. For example, a sticky substrate will form large agglomerates (clumps), which cannot be fluidized. ${ }^{111,116,117}$ In order to fluidize all, the solid substrate should have the same particles size. With size differences, some small size particles might fluidize and the large particles size might not fluidized. ${ }^{118}$ There is no problem with controlling the temperature and cooling the substrate bed, because high flow rates for fluidization should provide a large enough convective cooling capacity ${ }^{116,117}$ and good rate of heat and mass transfer. ${ }^{23}$ However, mixing steps in fluidized bed could damage the penetrative mycelium of the fungus because fungi are affected by hard force. ${ }^{101}$ The design scheme of the fluidized-bed bioreactor can be seen in Figure 6.

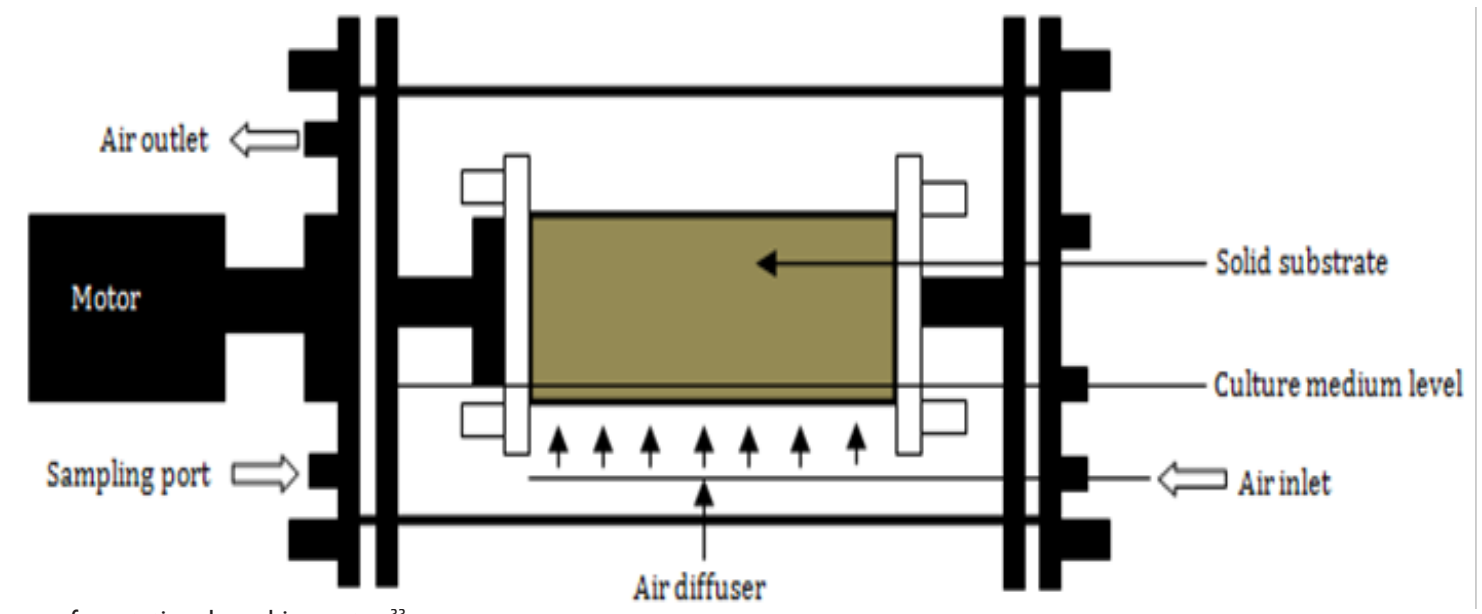

Figure 5 Scheme of a rotating drum bioreactor. ${ }^{33}$

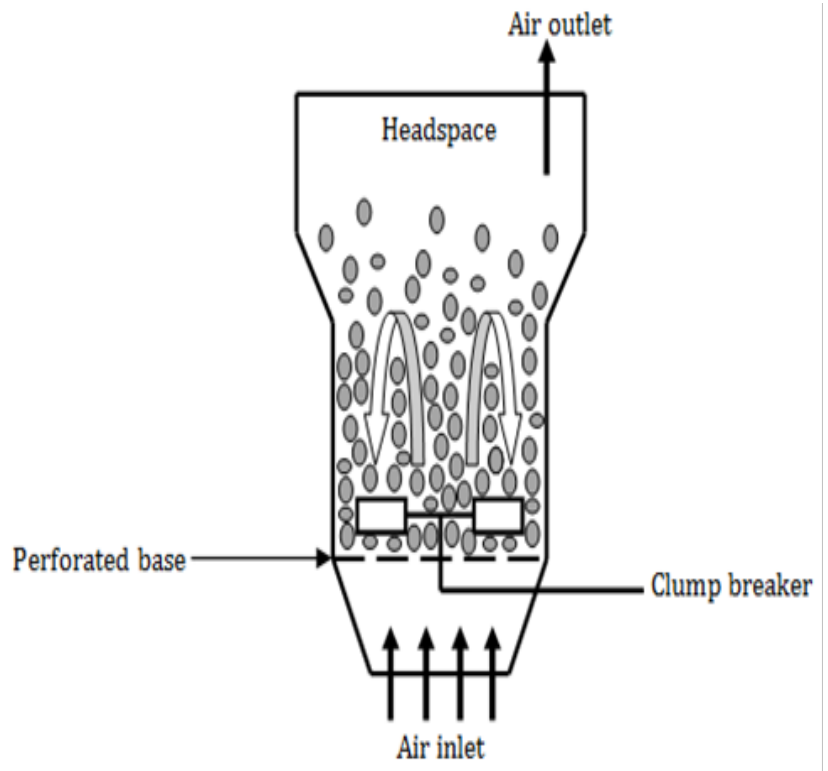

Figure 6 Scheme of a gas-solid fluidized-bed bioreactor. ${ }^{101}$

Spouted-bed bioreactors: In spouted-bed bioreactors, air is only blown upwards through the central axis of the solid bed. As a result, only part of the bed is fluidized and the bed can be expanded. Due to the vigorous contact between gas and solids, solids slip down the bottom of bioreactor due to its sloped sides and solids cycle continuously. ${ }^{100,101,119}$ The advantage of the spouted-bed bioreactor is that it prevents particles agglomeration caused by high-speed impacts in the spouted-bed's core region. ${ }^{23,120}$ This is suitable for handling solids, which have sticky nature, irregular texture or size distribution that cannot be treated in fluidized-bed bioreactors. ${ }^{119}$ Also spouted-bed bioreactors are able to handle large coarse solid particles, different densities and shapes, ${ }^{121}$ which are related to solid substrate for the SSF process. Furthermore, spouted-bed bioreactors have other advantages for mass and heat transfer. This is because exceptional mixing of solid substrates in the bioreactor creates high mass and heat transfer rates. ${ }^{119,120,122,123}$

The spouted bed bioreactor solves the problems of more common SSF carried out in tray and packed-bed bioreactors. ${ }^{124}$ Spouted bed bioreactor show improved fermentation performance, including higher product titers, yields, and productivity. ${ }^{125}$ They studied the spouted-bed bioreactor with intermittent spouting with air, which achieved high production levels both of total protein and enzymes. The result was similar to packed-bed bioreactor, but spouted-bed had uniformity and had no solids-handling problems. However, it was found that continual spouting was found to be unfavourable to this SSF, possibly because of shear impact damage to fungal mycelium during spouting. ${ }^{125}$ The design scheme of the spouted-bed bioreactor is illustrated in Figure 7.

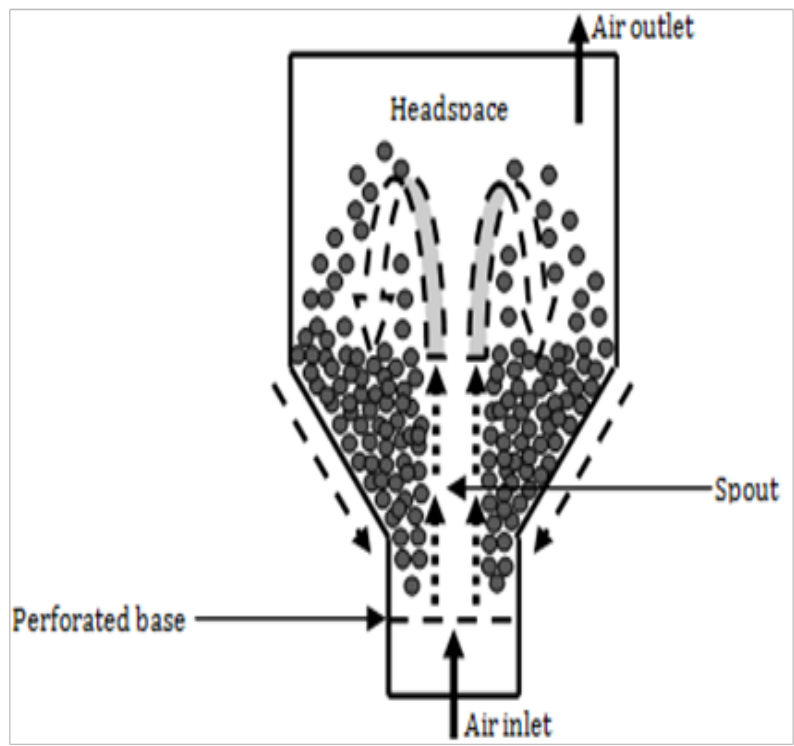

Figure 7 Scheme of a spouted-bed bioreactor. ${ }^{101}$ 
Table 6 lists common features and problems with SSF bioreactors. All designs are based on applying simple aeration and mixing strategies to the system, both for small scale and large scale. Particularly, packedbed, tray, rotating drum and fluidized-bed bioreactors gained great attention from researchers. Choosing the most suitable bioreactor system depends on which solid substrates and microorganisms are used in the SSF. ${ }^{126}$ Importantly, research and development are interested in improving performance and productivity, by improving existing SSF bioreactor systems and processes. ${ }^{127}$ The results of the research studies increase possibilities for improving quality of SSF bioreactor systems. Results are because of manipulation of the substrates or the microorganisms used. Bioreactor designs are more progressive, due to investments in design development. This is possible because of advantages of SSF, which have been discovered. Also because economic factors such as having choice of using wider ranges of raw materials. ${ }^{22}$ For the past 15 years, a lot of research has focused on bioreactor engineering to improve mixing, aeration, heat removal, moisture gradients and mass transfers, either in small or large scale SSF bioreactor. Mostly the research based on trial and error, or adopted from somewhere else. Some of the findings showed that a "new" system design and technology could be developed by manipulating the bioreactor systems and process. ${ }^{23}$ Despite progressive research, there are still many problems to be solved. These include problems with oxygen transfer, removing of metabolic heat and water activity distribution through the solid substrate particles. According to Mitchell et al., ${ }^{100}$ ideal balance can be created by: combining the most desired operating conditions within the SSF process with desired conditions in SSF bioreactors, needed for:

i. Minimizing deviations from the optimum temperature

ii. Minimizing damage to microorganism

iii. Minimizing deviations of the bed water activity from the optimum value and

iv. Maximizing the supply of oxygen to the solid substrate particles

Table 6 Features and problems of commonly used SSF bioreactors ${ }^{22,23,126}$

\begin{tabular}{|c|c|}
\hline Bioreactor type & Features/problems \\
\hline & Very simple, low cost, small quantity of substrate, less contamination, \\
\hline \multirow{7}{*}{$\begin{array}{l}\text { Bench scale: } \\
\text { Petri dish } \\
\text { Erlenmeyer flask }\end{array}$} & \\
\hline & Allows many experiments, passive aeration, easy regulation of temperature and airflow rate \\
\hline & \\
\hline & Optimisation of the process and experimental variables in a short time \\
\hline & Simple structure, easy to operate \\
\hline & Non-aeration, non-mixed \\
\hline & Heat accumulation \\
\hline \multirow[t]{7}{*}{ Tray bioreactor } & Temperature and moisture gradients generated \\
\hline & Bed caking \\
\hline & Required larger area \\
\hline & Labour intensive \\
\hline & Forced-aeration, non-mixed \\
\hline & Axial temperature and gas concentration gradients exist \\
\hline & Non-uniform growth \\
\hline \multirow{7}{*}{ Packed-bed bioreactor } & Difficulties to harvest the final product \\
\hline & Difficult to scale-up \\
\hline & Bed caking \\
\hline & Labour intensive \\
\hline & Packed-bed bioreactors with internal cooling plates \\
\hline & The spacing between the internal cooling plates and the temperature of the cooling water \\
\hline & Cooling water temperature is varied during fermentation in response to bed temperature \\
\hline \multirow[t]{4}{*}{ Zymotis bioreactor } & Overcomes the problem of heat removal \\
\hline & Substrate must be maintained static \\
\hline & Leads to reasonably stable bioreactor performance \\
\hline & High productivities at large scale - easy scaling up \\
\hline
\end{tabular}


Table Continued..

\begin{tabular}{|c|c|}
\hline Bioreactor type & Features/problems \\
\hline \multirow{8}{*}{ Rotating-drum bioreactor } & Continuously or intermittently mixed/agitation with forced-aeration \\
\hline & Improved mass and heat transfer \\
\hline & Considered to be better and more uniform \\
\hline & Operating on continuous or semi-continuous mode \\
\hline & Shear effect may cause damage to microorganisms \\
\hline & Slumping flow may cause a little mixing \\
\hline & Complicated reactor construction \\
\hline & Difficult operation for large scale fermentation \\
\hline \multirow{8}{*}{ Fluidized-bed bioreactor } & Good moisture and temperature controlling due to good mixing \\
\hline & High mass and heat transfer rate \\
\hline & Removal of metabolic heat is efficient \\
\hline & Excellent growth of aerobic microorganisms due to efficient aeration \\
\hline & No bed caking \\
\hline & High shear damage to microorganisms \\
\hline & Difficult to fluidize large, coarse and sticky particles \\
\hline & High cost \\
\hline \multirow{5}{*}{ Spouted-bed bioreactor } & Continuously or intermittently mixed \\
\hline & High mass and heat transfer rate \\
\hline & Lower power requirements than fluidised-bed systems \\
\hline & Good in handling large, coarse, non-uniformly sized and sticky particles \\
\hline & Need further investigation on characterisation and scale-up \\
\hline
\end{tabular}

\section{Mass transfer phenomena in Ssf}

Performance of SSF depends greatly upon issues such as mass transfer phenomena and bioreaction rates, as well as effective bioreactors system design and operation. 'Micro-scale' and 'macroscale' are used to describe mass transfer within the SSF bioreactor system. Figure 8 shows the relationship between micro-scale and macro-scale phenomena. According to Mitchell et al: ${ }^{4}$

i. 'Micro-scale' involves microorganism growth which is affected by interaction between microorganisms and the local environment inside the solid substrate particles.

ii. 'Macro-scale' refers to effectiveness of SSF bioreactor system design and operation strategy and how this may affect conditions in local environment of microorganism.

Generally mass transfer phenomena in SSF are not easy to measure, because different phenomena take place at the same time. Also, the relative importance of phenomena changes with bioreactor type, scale and other factors. ${ }^{127}$

Micro-scale phenomena: Micro-scale phenomena are of great interest because they are a major disadvantage of SSF. Figure 9 shows the schematic of some micro-scale phenomena that happen during SSF (as illustrated by Hölker et al. ${ }^{128}$ SSF has three major phases: which are the solid, gas and liquid phase. These phases make the process quite complicated and varied. Following this thought, microorganisms have a limited access to nutrients contained in the solid substrate, oxygen, water, enzymes and also limited carbon dioxide and heat removal. This will lead to poor growth, reduced bioreaction rates, low productivity and poor performance of the bioreactor system due to these limitations. In this situation, where SSF involves the use of fungi, mass transfers in micro-scale phenomena can be classified into four categories:
i. Intra-particle mass transfer
ii. Inter-particle mass transfer
iii. Heat transfer and
iv. Water transfer

Inter-particle mass transfer: In SSF systems, the liquid film on the substrate surface limits oxygen transfer. Oxygen mostly comes from the gas phase and also from that dissolved in water due to growth and metabolism of the culture. ${ }^{127}$ However, compared to SMF, in SSF, gas transfer is much higher due to high interfacial area-to-liquid volume ratios of solid substrate particles. ${ }^{129-131}$ During the fermentation process, the microorganism consumes oxygen, decreasing oxygen concentrations. Levels become less and less along the penetration depth, possibly reaching zero at a certain depth. Increasing oxygen transfer can increase penetration depth of the mycelium. ${ }^{131}$ Gas volume within solid substrate particles inside bioreactors represents the void fraction. The void space depends on the solid substrate particle characteristics and also moisture content. ${ }^{132,133}$ Moisture content should be optimum; not too high or too low. If the moisture level becomes too high, void space becomes filled with water, causing oxygen concentration to decrease greatly. Conversely, if the moisture content is too low, the growth of the microorganism will be negatively affected, even though the space between solid particles becomes filled with sufficient oxygen. ${ }^{134}$ 


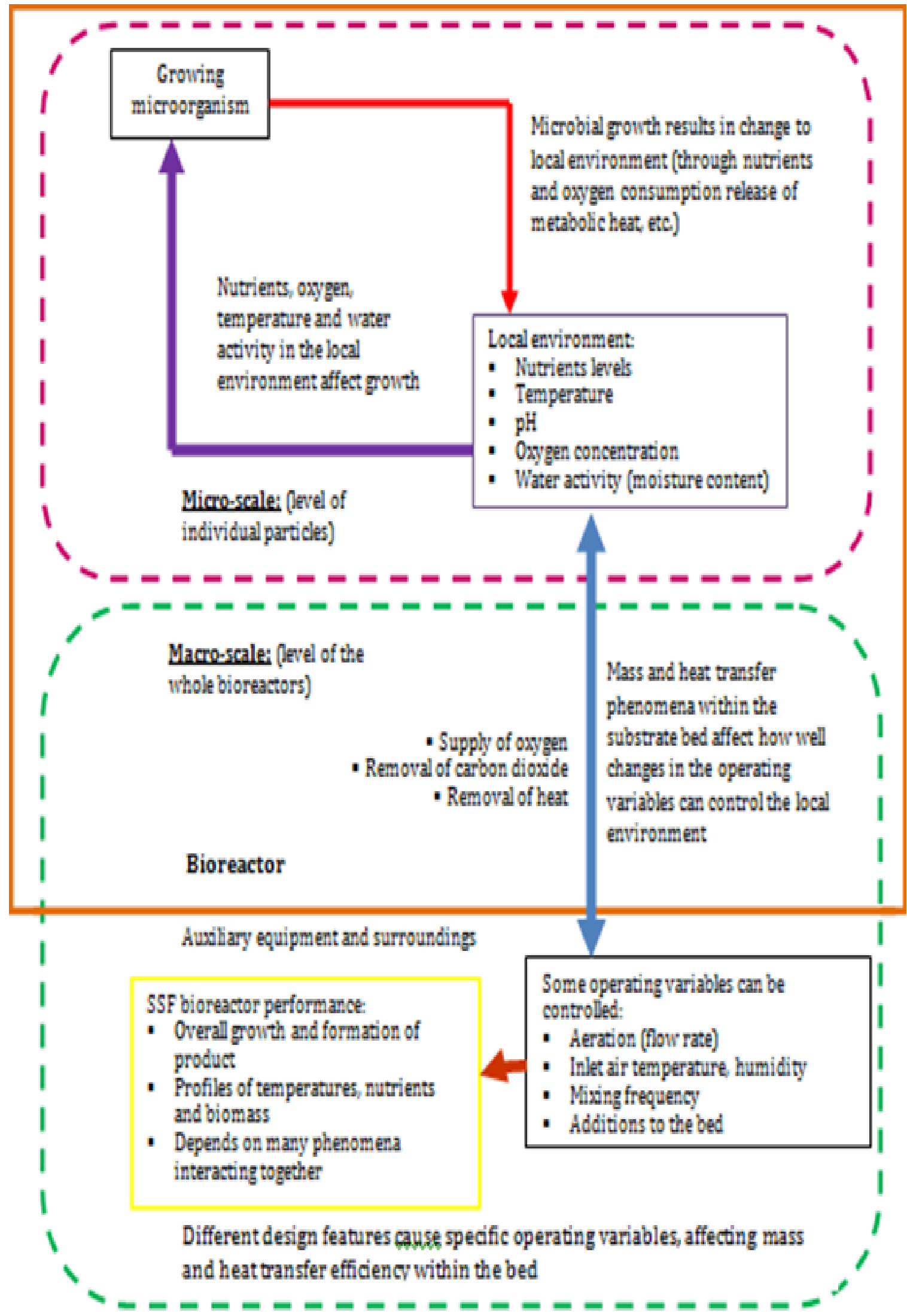

Figure 8 Summary of the micro-scale and macro-scale interactions between different factors that can affect SSF systems performance. ${ }^{4}$ 


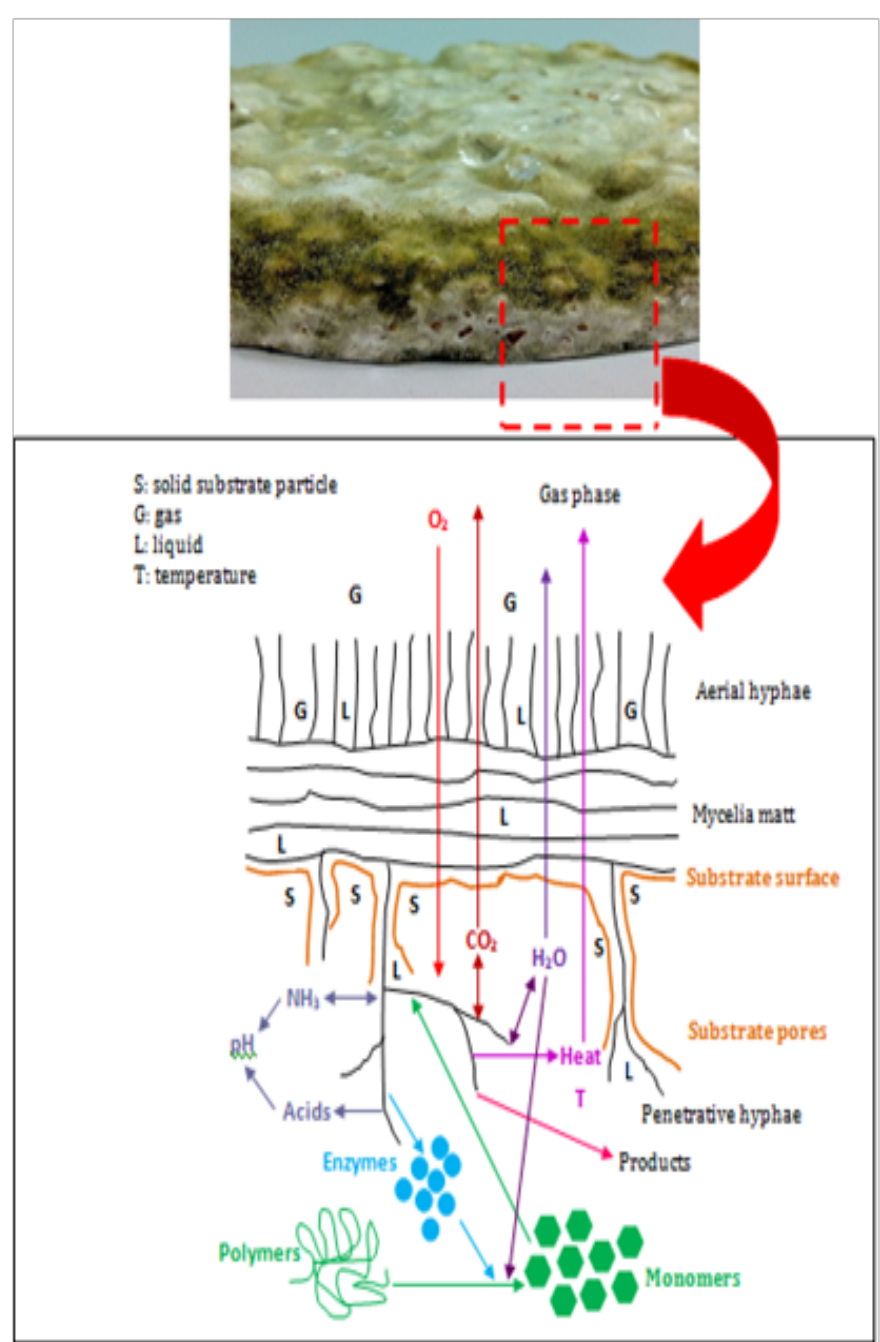

Figure 9 Schematic of the micro-scale processes that occur during SSF involving fungi. ${ }^{128}$ Above fermented wheat bran with Aspergillus oryzae from the current study.

In SSF, inter-particle mass transfer involves oxygen transfer to the growing fungus from the void fraction within the solid substrate particles. Internal oxygen concentration plays a very important role. Oxygen first passes through the actively respiring biomass in the solid substrate particle surface and subsequently diffuses through the liquid phase of the substrate..$^{90}$ Aeration and mixing are a good method to cause inter-particle oxygen transfer under the correct conditions of parameters such as void fraction and moisture content. Both continuous or intermittent mixing and aeration will resupply oxygen required for respiration. ${ }^{135}$ In addition, these processes function to prevent the exhaustion of oxygen in localised regions of the solid substrate particles. At the same time, they represent a good way to release the entrapped metabolic heat and carbon dioxide.

Intra-particle mass transfer: Intra-particle mass transfer concerns transfer of nutrients and enzymes inside solid substrate particles. Here, the main issue is the diffusion of oxygen needed in metabolic respiration. Oxygen is consumed and carbon dioxide, water, heat and other products are produced. Additionally, the substrate containing the biomass produces enzymes, other polymers and secondary metabolites. The growing microorganisms secrete further enzymes, which help in the biodegradation of solid substrate particles. According to Mitchell et al., ${ }^{136}$ there are three steps of intra-particle mass transfer:

i. Enzymes are released from the mycelium

ii. Enzyme diffusion and

iii. The process of degrading the substrate

The degradation process happening inside the solid substrate and the pore space between solid substrate particles improves nutrients and enzyme diffusion. Using small particles decreases the diffusion of solutes including enzymes, nutrients and oxygen. ${ }^{4}$ Porosity of solid substrate particles changes during the course of SSF. Due to this, the rate of diffusion of oxygen, nutrients and enzymes may vary. Diffusivity processes limit the growth rate, especially within the solid substrate particles. ${ }^{76,77}$ Another consideration is that solid substrate particles should have high enough moisture content. This will increase the chance of efficient diffusion processes for oxygen, nutrients and enzymes. According to Mitchell et al., ${ }^{4}$ high water content can help to improve diffusion coefficients. With respect to this, the physical morphology of the solid substrate particles changes during SSF, especially porosity and particle size, which influences how much of the surface area is accessible to oxygen, nutrients, enzymes and the microorganism itself. ${ }^{85,86}$

Heat transfer: During SSF, a high amount of metabolic heat is produced. The amount of heat depends on the metabolic activity levels of the microorganism. Heat builds up in the fermentation medium because the solid substrate is a good thermal conductor. ${ }^{87}$ The transfer of heat into or out of the SSF system is closely linked with the microorganism's metabolic activity, as well as the aeration of the fermentation system. During SSF, heat transfer is needed for temperature control. High temperature affects growth and product formation negatively. Low temperatures are unfavourable for growth and biochemical reactions. High moisture content in the SSF system makes it difficult to achieve good heat transfer. As fermentation progresses, oxygen diffuses and undergoes bio-reactions, which release heat. At the same time, solid substrate particles shrink, reducing porosity, which further reduces heat transfer. Under these circumstances, heat builds up in the system. Mixing and aeration are good strategies because they lead to high rates of both heat removal and oxygen supply. Mixing or aeration with saturated air is an efficient solution, which helps with temperature control. Mitchell et al. ${ }^{4}$ suggest a strategy that promotes convective heat and mass transfer in the substrate bed through bulk flow of gas through the inter-particle spaces. As a result, controlling the bed temperature is more effective compared to strategies that restrict heat and mass transfer within the bed (reducing conduction and diffusion).

Water transfer: During SSF, there are four factors, which aid status and water balance inside the system. ${ }^{137}$ These include water level in the hydrolysis step, metabolic water production, uptake of intracellular water during biomass production and metabolic-heat production causing water evaporation (Figure 10). It is important to keep water content at an optimal level to avoid poor growth in SSF. Gervais et al. ${ }^{138}$ describe water activity as a 'water potential', with osmotic and matric functions. The first function is due to dissolved solutes and the second one is due to capillary forces. Monitoring water activity or moisture content and solute concentration can help to keep the water potential at the right level for SSF. ${ }^{139,140}$ However, water activity decreases with fermentation time. This is due to the evaporation of water on removing heat of the fermented substrate. At 
the same time (in almost all cases), heat builds up in the system and causes condensation and therefore water, as can be seen in Figure 11. This water returns back into the fermentation bed, however this water collects unevenly in the solid substrate and causes irregularly formed areas. In areas of greater water content, the growth of microorganisms becomes disrupted. In practice, a solution for this problem involves controlling temperature by supplying air into the bioreactor which influences water activity in SSF. Usually, cooling air is used and a high amount of air is able to overcome the problem.

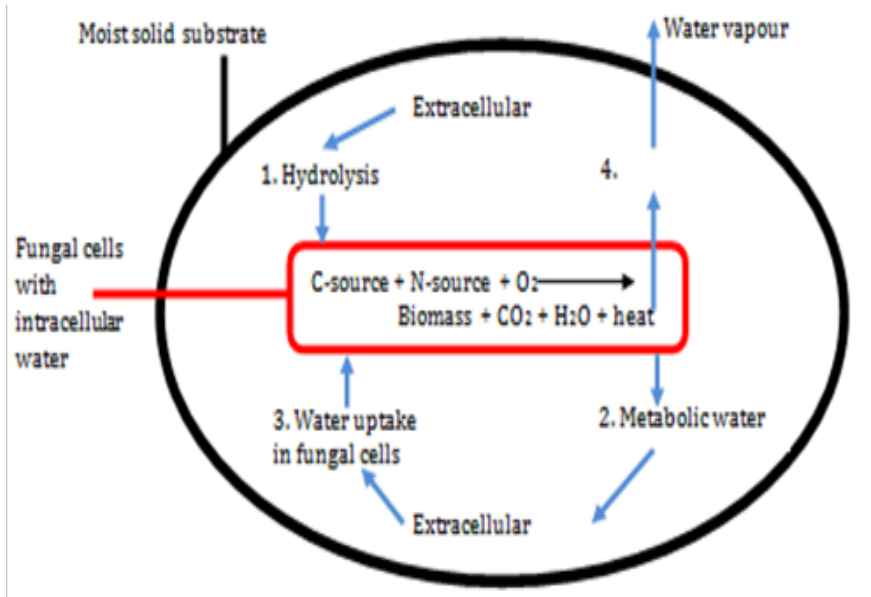

Figure I0 A schematic overview of the four different contributions in water balance during SSF. ${ }^{137}$

Macro-scale phenomena: Macro-scale phenomena describe how effective the design and operation strategy of the SSF bioreactor system are and how they affect conditions in the microorganism's local environment (such as provision for aeration, mixing or agitation and heat removal). According to Mitchell et al., ${ }^{6}$ macro-scale phenomena refer to several situations and issues faced by SSF bioreactor systems.

i. The movement of air into and out of the bioreactor can affect how well bulk transport, especially of oxygen, carbon dioxide, water and heat, occurs. Usually, it occurs in the headspace or inter-particle spaces depending on the bioreactor type.

ii. If the bioreactor is operated with forced aeration, this can influence how effective bulk transport is, especially inter-particle transport. Dry forced air can cause large moisture losses and drying of the solid substrate.

iii. If the bioreactor is operated with agitation or mixing, two important criteria need to be taken into account. First, the solid substrate particles must cope with shear stress and must not coagulate after agitation or mixing. Second, the microorganisms should be able to cope with shear stress, otherwise mixing or agitation could damage them.

iv. Bulk transport could happen as a result of natural conduction, convection, and diffusion.

v. Bulk heat transport through conduction across bioreactor walls to the surrounding can occur.

vi. Convective cooling across the bioreactor walls to the surrounding can also occur.

vii. Physical properties of the solid substrate such as density, porosity (void space) and stickiness change during fermentation. Also, oxygen can only move by diffusion once it is transferred from the gas phase into the liquid phase within the particle. ${ }^{4}$
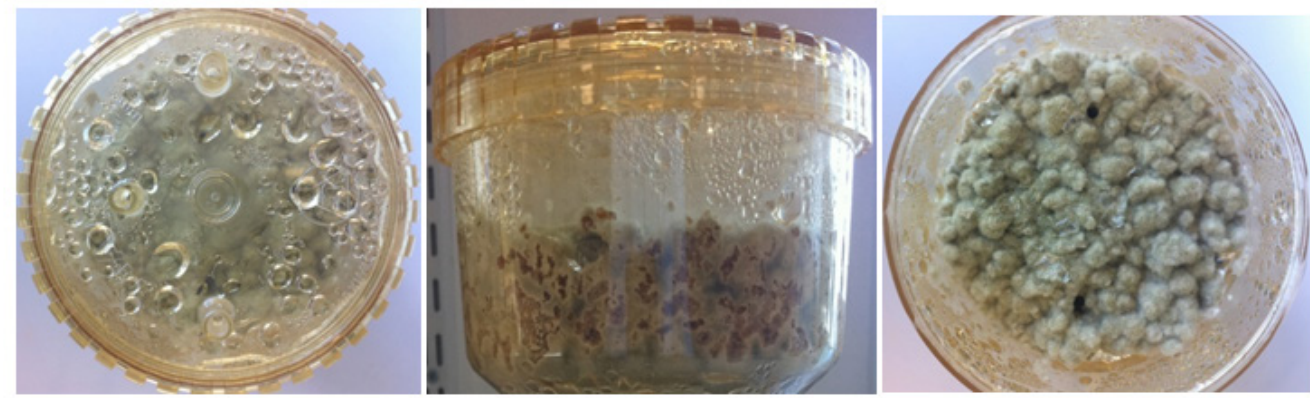

Figure I I Water formation in the bioreactor system.

\section{A. On the lid \\ B. On the wall and \\ C. Inside the bioreactor.}

\section{Future hopes}

The decade of 1980-1990 (Table 1), witnessed a remarkable growth in research activities on SSF technology for the production of various primary and secondary metabolites. The development of various types of fermenters as well as forming new theories on kinetics and modelling was observed. Since 1990, the entire focus has changed, placing more emphasis on the development of bioprocess via SSF. This phenomenon includes research on SSF as a tool in biorefinery development for bioethanol and biofuel production. The research on SSF and some of the results have provided a weighty contribution to improving existing and widely used technology. To a certain extent, the types of research activities have increased due to some of the recent research findings. This has created a better understanding of the existing SSF process and provided future development opportunities. However, it is not possible to carry out a detailed analysis of SSF because the history, research development and scientific investigation of SSF are varied and inconsistent, despite being explored and reviewed time and again by many scientists. SSF bioreactor systems for the production of enzymes and secondary metabolites were previously an important area of development of the SSF process technology. The popularity of SSF technology increased as a result of several advantages and despite its drawbacks. Current research on biorefineries based on SSF has the aim of using generic fermentation feedstock to produce a range of potential added value end products. This later application 
shows great potential especially in biochemical industries. Such application will lead to a promising future for SSF technology as an integral part of such biorefineries.

Many microorganisms including bacteria and fungi were found to be capable of producing many miscellaneous compounds. The most important is the ability of these microorganisms to degrade waste solids directly. For this purpose, SSF technology has been applied successfully and is gaining momentum rapidly. Another area where SSF technology can be fully exploited is in the manufacture of SSF bioreactor systems with features to suit the specific microorganism used. SSF bioreactors may lead to an industrial feasibility. This in turn presents some bioengineering challenges since a variety of bioreactors need to be designed and implemented for SSF metabolic production. The opportunity to produce new products via manipulation of culture conditions, fermentation process development, media development, bioreactor design coupled with efficient downstream processing and product recovery will be a unique challenge for new areas of SSF technology. SSF proved to be excellent technology for solid wastes treatment. It can be suggested that utilisation of food and agro-industry solid waste can be carried out for the production of various added-value products. Industrial bodies should consider this scenario as part of their strategy for tackling the food and agro-industry waste problem and for the environmentally friendly production of enzymes, secondary metabolites, chemicals and even bio-fuels. Therefore, this can overcome the issues of the solids wastes being thrown into the land, which can create another problem for the environment.

\section{Conclusion}

Advances in the understanding of microbiology and of the composition of targeted products and their raw materials (biomass), as well as the development of advanced SSF bioreactor, allow more consistent research and development on SSF. Thus, we arrive at the modern day bioprocessing and microbial fermentation processes. Despite many limitations, many industrial facilities worldwide successfully operate SSF processes, although some of them produce relatively small quantities of high added-value products that do not require large-scale bioreactors. In other cases, the bioreactors do not operate optimally, or bioreactors that are not easily adaptable for different processes are used. We believe that in the near future flexible and optimum performance large-scale SSF bioreactors will be designed, built and operated successfully, although more engineering research is needed. These bioreactors will use low-cost and reliable instruments, especially designed for SSF, and sophisticated control strategies that will include advanced control techniques such as expert and model based controlled systems. The ability of microorganisms, especially filamentous fungi, to convert biomass through SSF bioconversion will have a great impact on food and agro-industry in every aspect of life from food and medicine to fuel. This is a future that undoubtedly will present challenges, but one that I believe we should embrace.

\section{Acknowledgements}

To the Malaysian Agricultural Research and Development Institute (MARDI) and Government of Malaysia for providing me an opportunity to further study and financial support during my study.

\section{Competing interest}

The authors declare that there is no conflict of interests regarding the publication of this paper.

\section{References}

1. Krishna C. Solid-state fermentation system- an overview. Crit Rev Biotechnol. 2005;25(1-2):1-30.

2. Hongzhang C. Modern solid state fermentation: Theory and practice. New York, USA: Springer Dordrecht Heidelberg; 2013. p. 1-242.

3. Oostraa J, Tramper J, Rinzema A. Model-based bioreactor selection for large-scale solid-state cultivation of Coniothyrium minitans spores on oats. Enzyme Microb Technol. 2000;27(9):652-663.

4. Mitchell DA, De Lima Luz LF, Krieger N. Bioreactors for solid-state fermentation. In: Moo-Yong M, editor. Comprehensive Biotechnology. 2nd ed. UK: Elsevier; 2011. p. 347-360.

5. Pandey A, Carlos R Soccol, David Mitchell. New developments in solid state fermentation. I: processes and products. Process Biochemistry. 2000;35(10):1153-1169.

6. Mitchell DA, Berovic M, Krieger N. Biochemical engineering of solid state bioprocessing. Adv Biochem Eng Biotechnol. 2000;68:61-138.

7. Viniegra-Gonzàlez G. Solid state fermentation: Definition, characteristics, limitations and monitoring. In: Roussos S, et al. editors. Advances in solid state fermentation (Chapter 2). Dordrecht, Netherlands: KIuwer Academic Publishers; 1997. p. 5-22.

8. Rahardjo YS, Tramper J, Rinzema A. Modeling conversion and transport phenomena in solid-state fermentation: A review and perspectives. Biotechnol Adv. 2006;24(2):161-179.

9. Rosales E, Rodríguez Coutob S, et al. Increased laccase production by Trametes hirsuta grown on ground orange peelings. Enzyme and Microbial Technology. 2007;40(5):1286-1290.

10. Thomas L, Larroche C, Ashok Pandey. Current developments in solid-state fermentation. Biochemical Engineering Journal. 2013;81:146161.

11. Ashok A, Kruthi Doriya, Devulapally Ram Mohan Rao, et al. Design of solid state bioreactor for industrial applications: An overview to conventional bioreactors. Biocatalysis and Agricultural Biotechnology. 2017;9:11-18

12. Pandey A, Soccol CR, Laroche C. General and fundamentals aspects of SSF-Introduction. In: Pandey A, et al. editors. Current development in solid-state fermentation. Germany: Springer Science+ Business Media; 2008. p. 3-12.

13. Pandey A, Soccol CR, Larroche C. Preface. In: Pandey A, et al. editors. Current developments in solid-state fermentation. New Asiatech Publishers Inc., Delhi, India: Springer; 2008. p. 3-6.

14. Sattar Qureshi A, Khushk I, Haider Ali C, et al. Coproduction of protease and amylase by thermophilic Bacillus sp. BBXS-2 using open solid-state fermentation of lignocellulosic biomass. Biocatalysis and Agricultural Biotechnology. 2016;8:146-151.

15. Castilho LR, Polato CMS, Baruque EA, et al. Economic analysis of lipase production by Penicillium restrictum in solid-state fermentation and submerged fermentation. Biochemical Engineering Journal. 2000;4(3):239-247.

16. Bhanja Dey T, Chakraborty S, Jain KK, et al. Antioxidant phenolics and their microbial production by submerged and solid state fermentation process: A review. Trends in Food Science \& Technology. 2016;53:6074.

17. Viniegra-González G, Favela-Torres E, Noe Aguilar C, et al. Advantages of fungal enzymes production in solid state over liquid fermentation systems. Biochemical Engineering Journal. 2003;13(2-3):157-167.

18. Singhania RR, Sukumaran RK, Patel AK, et al. Advancement and comparative profiles in the production technologies using solid-state and submerged fermentation for microbial cellulases: Review. Enzymes and Microbial Technology. 2010;46(7):541-549. 
19. Soares LH, Assmann F, Ayub MA. Production of transglutaminase from Bacillus circulans on solid-state and submerged cultivations. Biotechnol Lett. 2003;25(23):2029-2033.

20. Carlile MJ, Watkinson SC, Gooday GW. The fungi as a major group of microorganisms. 2nd ed. San Diego, California, USA: Academic Press; 2001. p. 1-7.

21. Kelecom A. Secondary metabolites from marine microorganism. An Acad Bras Cienc. 2002;74(1):151-170.

22. Nee Nigam PS, Ashok Pandey. Solid-state fermentation technology for bioconversion of biomass and agricultural residues. In: Nigam PS, et al editors. Biotechnology for Agro-Industrial Residues Utilisation. Germany: Springer Science + Business Media; 2009. p. 197-221.

23. Wang L, Yang ST. Solid state fermentation and its application. In: Yang ST, editor. Bioprocessing for value-added products from renewable resources. UK: Elsevier; 2007. p. 465-489.

24. Visintin S, Ramos L, Batista N, et al. Impact of Saccharomyces cerevisiae and Torulaspora delbrueckii starter cultures on cocoa beans fermentation. Int J Food Microbiol. 2017;257:31-40.

25. Asmahan A Ali, Muna M Mustafa. Use of starter cultures of lactic acid bacteria and yeasts in the preparation of Kisra, a Sudanese fermented food. Pakistan Journal of Nutrition. 2009;8(9):1349-1353.

26. Crafack M, Hanna Keul, Eskildsen CE, et al. Impact of starter cultures and fermentation techniques on the volatile aroma and sensory profile of chocolate. Food Research International. 2014;63(part C):306-316.

27. Sekiguchi J, Gaucher GM. Conidiogenesis and secondary metabolism in Penicillium urticae. Appl Environ Microbiol. 1977;33(1):147-158.

28. Smith GM, Calam CT. Variations in inocula and their influence on the productivity of antibiotic fermentations. Biotechnology Letters. 1980;2(6):261-266.

29. Nigam P, Singh D. Solid-state (substrate) fermentation systems and their applications in biotechnology. J Basic Microbiol. 1994;34(6):405-423.

30. Mitchell DA, Berovic M, Krieger N. Overview of solid state bioprocessing. Biotechnol Annu Rev. 2002;8:183-225.

31. Florian Zepf, Bo Jin. Bioconversion of grape marc into protein rich animal fedd by microbial fungi. Chem Eng Process Tech. 2013;1(2):1011.

32. Rodríguez Couto S. Exploitation of biological wastes for the production of value-added products under solid-state fermentation condition: Review. Biotechnol J. 2008;3(7):859-870.

33. Rodríguez Couto S, Ma Ángeles Sanromán. Application of solid-state fermentation to food industry- A review. Journal of Food Engineering. 2006;76(3):291-302.

34. Peričin D, Mađarevpopović S, Radulovi Popović L, et al. Evaluate of pumpkin oil cake as substrate for the cellulase production by Penicillium roqueforti in solid state fermentation. Roumanian Biotechnological Letters. 2012;13(4):3815-3820.

35. Borucki Castro SI, Phillip LE, Lapierre H, et al. Ruminal degradability and intestinal digestibility of protein and amino acids in treated soybean meal products. J Dairy Sci. 2007;90(2):810-822.

36. Nagamani B, Chandana Lakshmi MVV, Sridevi V, et al. Production of protease from sesame oil cake by Penicillium chrysogenum under solid state fermentation. IJCEPr. 2012;3(2):137-141.

37. Adinarayana K, Raju KVVSN Bapi, Zargar M Iqbal, et al. Optimization of process parameters for production of lipase in solid-state fermentation by newly isolated Aspergillus species. IJBT. 2004;3(1):65-69.

38. Batal A, Dale N, Cafe M. Nutrient composition of peanut meal. JAPR. 2005;14(2):254-257.
39. Sivaramakrishnan S, Gangadharan D. Edible oil cakes. In: Nigam PS, et al. editors. Biotechnology for Agro-Industrial Residues Utilisation. Germany: Springer Science+Business Media; 2009. p. 253-271.

40. Shi C, He J, Yu J, et al. Physicochemical properties analysis and secretome of Aspergillus niger in fermented rapeseed meal. PLoS One. 2016;11(4):e0153230.

41. Ramachandran S, Roopesh K, Nampoothiri KM, et al. Mixed substrate fermentation for the production pf phytase by Rhizopus spp. using oil cakes as substrates. Process Biochemistry. 2005;40(5):1749-1754.

42. Ramachandran S, Singh SK, Larroche C, et al. Oil cakes and their biotechnological applications- A review. Bioresour Technol. 2007;98(10):2000-2009.

43. Rani R, Ghosh S. Production of phytase under solid-state fermentation using Rhizopus oryzae: Novel strain improvement approach and studies on purification and characterization. Bioresour Technol. 2011;102(22):10641-10649.

44. Ghosh S, Murthy S, Govindasamy S, et al. Optimization of L-asparaginase production by Serratia marcescens (NCIM 2919) under solid state fermentation using coconut oil. Sustainable Chemical Processes. 2013;1:9.

45. Sunday Dairo FA, Fasuyi A. Evaluation of fermented palm kernel cake meal and fermented copra meal proteins as substitute for soybean meal protein in laying hens diets. Journal of Central European Agriculture. 2008;9(1):35-44.

46. Moftah OA, Grbavčić S, Zuža M, et al. Adding value to the oil cake as a waste from oil processing industry: Production of lipase and protease by Candida utilis in solid state fermentation. Appl Biochem Biotechnol. 2012;166(2):348-364

47. Singhania RR, Sukumaran RK, Anu Pillai, et al. Solid-state fermentation of lignocellulosic substrates for cellulose production by Trichoderma reesei NRRL 11460. Indian Journal of Biotechnology. 2006;5(Suppl):332-336

48. Nurudeen OO, Adetayo OM, Rofiat Bolanle AS, et al. Cellulase and biomass production from sorghum (Sorghum guineense) waste by Trichoderma longibrachiatum and Aspergillus terreus. Journal of Microbiology Research. 2015;5(6):169-174.

49. Nadagouda MG, Lingappa K, Bheemareddy VS, et al. Optimization of solid state fermentation conditions for the production of cellulose by using Trichoderma viride GSG12. Bioscience Discovery. 2016;7(1):1-6.

50. Pensupa N, Jin M, Kokolski M, et al. A solid state fungal fermentation-based strategy for the hydrolysis of wheat straw. Bioresour Techno. 2013;149:261-267.

51. Williams K, Zheng Y, McGarvey J, et al. Ethanol and volatile fatty acid production from lignocellulosic by Clostridiun cellulolyticum. ISRN Biotechnology. 2013;2013:1-7.

52. Santos TCD, Filho GA, De Brito AR, et al. Production and characterization of cellulolytic enzymes by Aspergillus niger and Rhizopus sp. by solid state fermentation of prickly pear. Revista Caatinga, Mossoro. 2016;29(1):222-233.

53. Saratale GD, Saratale RG, Ghodake GS, et al. Solid state fermentative lignocellulolytic enzymes production, characterization and its application in the saccharification of rice waste biomass for ethanol production: An integrated biotechnological approach. Journal of the Taiwan Institute of Chemical Engineers. 2017;76:51-58.

54. Montoya S, Sanchez OJ, Levin L. Production of lignocellulolytic enzymes from three white-rot fungi by solid-state fermentation and mathematical modelling. African Journal of Biotechnology. 2015;14(5):1304 1317 . 
55. Zuchowski J, Pecio L, Jaszek M, et al. Solid-state fermentation of rapeseed meal with the white-rot fungi Trametes versicolor and Pleurotus ostreatus. Applied Biochemistry and Biotechnology. 2013;171(8):20752081.

56. Dinis MJ, Bezerra RMF, Nunes F, et al. Modifictaion of wheat straw lignin by solid state fermentation with white-rot fungi. Bioresour Technol. 2009;100(20):4829-4835.

57. Gupte A, Gupte S, Patel H. Ligninolytic enzyme production under solid-state fermentation by white rot fungi. Journal of Scientific and Industrial Research. 2007;66(8):611-614.

58. Xu X, Yu Y, Shi Y. Evaluation of inert and organic carriers for Verticullium lecanii spore production in solid-state fermentation. Biotechnol Lett. 2011;33(4):763-768.

59. Weber FJ, Oostra J, Tramper J, et al. Validation of a model for process development and scale-up of packed-bed solid-state bioreactors. Biotechnol Bioeng. 2002;77(4):381-393.

60. Ooijkaas LP, Weber FJ, Buitelaar RM, et al. Defined media and innert support: Their potential as solid-state fermentation production systems. Trends Biotechnol. 2000;18(8):356-360.

61. Hu T, Zhou Y, Dai L, et al. Enhanced cellulose production by solid state fermentation with polyurethane foam as inert supports. Procedia Engineering. 2011;18:335-340.

62. Subbalaxmi S, Murthy VR. Process optimization for tannase production by Bacillus gottheilii M2S2 on inert polyurethane foam support. Biocatalysis and Agricultural Biotechnology. 2016;7:48-55.

63. Ganaie MA, Oliveira Hsganlts, Rawat HK, et al. Screening of low cost agricultural wastes to maximize the fructosyl transferase production and its applicability in generation of fructo-oligosaccharides by solid state fermentation. International Biodeterioration and Biodegradation. 2017;118:19-26.

64. Chen HZ, He Q. Value-added bioconversion of biomass by solid-state fermentation. Journal of Chemical Technology and Biotechnology. 2012;87(12):1619-1625.

65. Gervais P, Molin P. The role of water in solid-state fermentation. Biochemical Engineering Journal. 2003;13(2-3):85-101.

66. Manpreet S, Sawraj S, Sachin D, et al. Influence of process parameters on the production of metabolites in solid-state fermentation. Malaysian Journal of Microbiology. 2005;1(2):1-9.

67. Ruijiter GJ, Visser J, Rinzema A. Polyol accumulation by Aspergillus oryzae at low water activity in solid-state fermentation. Microbiology. 2004;150(4):1095-1101.

68. Divate RD, Wang CC, Chou ST, et al. Using wheat bran and soybean meal as solid state fermentation substances for the production of Xylaria nigripes with bioactivities. Journal of Taiwan Institute of Chemical Engineers. 2017;70:127-133.

69. Mitchell DA, Tongta A, Stuart DM, et al. The potential for establishment of axial temperature profiles during solid-state fermentation in rotating drum bioreactors. Biotechnol Bioeng. 2002;80(1):114-122.

70. Behera SS, Ray RC. Solid state fermentation for production of microbial cellulases: Recebt advances and improvement strategies. Int J Biol Macromol. 2016;86:656-669.

71. Durand A. Bioreactor designs for solid state fermentation. Biochemical Engineering Journal. 2003;13(2-3):113-125.

72. Villegas E, Aubaque S, Alcantra L, et al. Solid state fermentation: acid protease production in controlled $\mathrm{CO}_{2}$ and $\mathrm{O}_{2}$ environments. Biotechnol Adv. 1993;11(3):387-397.
73. Pandey A, Soccol CR, Rodriguez-Leon JA, et al. Aspects of design of fermenter in solid-state fermentation. Solid-state fermentation in Biotechnology: Fundamentals and Application. 1st ed. New Delhi, India: Asistech Publishers; 2001. p. 73-77.

74. Montero AF, Esparza-Isunza T, Saucedo-Castaneda G, et al. Improvement of heat removal in solid-state fermentation tray bioreactors by forced air convection. Journal of Chemical Technology and Biotechnology. 2011;86(10):1321-1331.

75. Finkler ATJ, Biz A, Pitol LO, et al. Intermittent agitation contributes to uniformity across the bed during pectinse production by Aspergillus niger grown in solid-state fermentation in a pilot-scale packed-bed bioreactor. Biochemical Engineering Journal. 2017;121:1-12.

76. Khanahmadi M, Roostaazad R, Mitchell DA, et al. Bed moisture estimation by monitoring of air stream temperature rise in packed-bed solid-state fermentation. Chemical Engineering Science. 2006;61(17):5654-5663.

77. Khanahmadi M, Roostaazad R, Safekordi A, et al. Investigating the use of cooling surfaces in solid-state fermentation tray bioreactors: Modelling and experimentation. Journal of Chemical Technology and Biotechnology. 2004;79(11):1228-1242.

78. Castro AM, Castilho LR, Freire DMG. Performance of a fixed-bed solid-state fermentation bioreactor with forced aeration for the production of hydrolases by Aspergillus awamori. Biochemical Engineering Journal. 2015;93:303-308.

79. Shojaosadati SA, Hamidi-Esfahani Z, Hejazi P, et al. Evaluation of strategies for temperature and moisture control in solid state packed bed bioreactors. Iranian Journal of Biotechnology. 2007;5(4):219-225.

80. Nava I, Favela-Torres E, Saucedo-Castaneda G. Effect of mixing on solid-state fermentation of coffee pulp with Aspergillus tamarii. Food Technology and Biotechnology. 2011;49(3):391-395.

81. Von Meien OF, Luz LFL, Mitchell DA, et al. Control strategies for intermittently mixed, forcefully aerated solid-state fermentation bioreactors based on the analysis of a distributed parameter model. Chemical Engineering Science. 2004;59(21):4493-4504.

82. Assamoi AA, Destain J, Delvigne F, et al. Solid-state fermentation of xylanase from Penicillium canescens 10-10c in a multi-layer-packed bed reactor. Applied Biochem and Biotechnol. 2008;145(1-3):87-98.

83. Gutarra MLE, Cavalcanti EDC, Castilho LR, et al. Lipase production by solid-state fermentation. Applied Biochem Biotechnol. 2005;121124:105-116.

84. Zhang X, Mo H, Zhang J, et al. A solid-state bioreactor coupled with forced aeration and pressure oscillation. Biotechnol Lett. 2003;25(5):417-420.

85. Umsza-Guez MA, Diaz AB, de Ory I, et al. Xylanase production by Aspergillus awamori under solid state fermentation conditions on tomato pomace. Brazillian Journal of Microbiology. 2011;42(4):1585-1597.

86. Richard TL, Veeken AHM, de Wilde V, et al. Air-filled porosity and permeability relationships during solid-state fermentation. Biotechnol Prog. 2004;20(5):1371-1381.

87. Ramana Murthy MV, Karanth NG, Raghavarao KSMS. Biochemical engineering aspects of solid-state fermentation. Advances in Applied Microbiology. 1993;38:100-147.

88. Karimi A, Shojaosadati SA, Hejazi P, et al. Porosity changes during packed bed solid-state fermentation. Journal of Industrial and Engineering Chemistry. 2014;20(6):4022-4027.

89. Schmidt CG, Furlong EB. Effect of particle size and ammonium sulphate concentration on rice bran fermentation with the fungus Rhizopus oryzae. Bioresource Technology. 2012;123:36-41. 
90. Rahardjo YSP, Jolink F, Haemers S, Tramper J, et al. Significance of bed porosity, bran and specific surface area in solid-state cultivation of Aspergillus oryzae. Biomolecular Engineering. 2005;22(4):133-139.

91. Zhao HM, Guo XN, Zhu KX. Impact of solid state fermentation on nutritional, physical and flavour properties of wheat bran. Food Chemistry. 2017;217:28-36.

92. Suryanarayan S. Current industrial practice in solid state fermentations for secondary metabolite production: the Biocon India experience. Biochemical Engineering Journal. 2003;13(2-3):189-195.

93. Mitchell DA, Von Meien OF, Luz LFL, et al. The scale-up challenge for SSF bioreactors. In: Mitchell DA, et al. editors. Solid state fermentation bioreactors: Fundamentals of design and operation. Germany: Springer-Verlag Berlin Heidelberg; 2010. p. 57-64.

94. Gasiorek E. Effect of operating conditions on biomass growth during citric acid production by solid-state fermentation. Chemical Papers. 2008;62(2):141-146.

95. Musoni M, Destain J, Thonart P, et al. Bioreactor design and implementation strategies for the cultivation of filamentous fungi and the production of fungal metabolites: from traditional methods to engineered systems. Biotechnology, Agronomy, Society and Environment. 2015;19(4):430-442.

96. Bastos RG, Motta FL, Santana MHA. Oxygen transfer in the solid-state cultivation of D. monocerans on polyurethane foam as an inert support. Brazilian Journal of Chemical Engineering. 2016;33(4):793-799.

97. Mitchell DA, Berovic M. Solid state bioprocessing. In: Berovic M, et al. editors. Slovenia Comprehensive bioprocess Engineering. European Federation on Biotechnology: Working Group on Bioreactor Performance in collaboration with European Section on Biochemical Engineering Sciences, Germany: University of Ljubljana; 2010. p. 209-238.

98. Mitchell DA, Cunha LEN, Machado AVL, et al. A model-based investigation of the potential advantages of multi-layer packed beds in solid-state fermentation. Biochemical Engineering Journal. 2010;48(2):195-203.

99. Mitchell DA, Berovic M, Nopharatana M, et al. Introduction to solid-state fermentation bioreactors. In: Mitchell DA, et al. editors. Sol id-state fermentation bioreactors: Fundamentals of design and operation. Germany: Springer-Verlag Berlin Heidelberg; 2006. p. 33-43.

100. Mitchell DA, Krieger N, Marin Berovič, et al. Continuously-mixed, forcefully-aerated bioreactors. In: Mitchell DA, et al. editors. Solid-state fermentation bioreactors: Fundamentals of design and operation. Germany: Springer-Verlag Berlin Heidelberg; 2006. p. 115-128.

101. Tim Robinson, Poonam Nigam. Bioreactor design for protein enrichment of agricultural residues by solid state fermentation. Biochemical Engineering Journal. 2003;13(2-3):197-204.

102. Alcântara SR, Da Silva FLH. Solid state fermentation process for polygalacturonase production using tray bioreactor. Chemical Engineering Transactions. 2012;27:355-359.

103. Vaseghi Z, Najafpour GD, Mohseni S, et al. Production of active lipase by Rhizopus oryzae from sugarcane bagasse: Solid state fermentation in a tray bioreactor. Int J Food Sci Technol. 2013;48(2):283-289.

104. Ling Xie, Hong Mei Chen, Ji Bin Yang. Conidia production by Beau veria bassiana on rice in solid-state fermentation using tray bioreactor. Advanced Materials Research. 2013;610-613:3478-3482.

105. Zhang Chen H, Jian Xu, HuLi Z. Temperature control at different bed depths in a novel solid-state fermentation system with two dynamic changes of air. Biochemical Engineering Journal. 2005;23(2):117-122.

106. Ruiza HA, Rodríguez-Jasso RM, Rodríguez R, et al. Pectinase production from lemon peel pomace as support and carbon source in solid-state fermentation column-tray bioreactor. Biochemical Engineering Journal. 2012;65:90-95.
107. Gutiérrez-Rojas M, Amar AboulHosn S, Auria R, et al. Heat transfer in citric acid production by solid state fermentation. Process Biochemistry. 1996;31(4):363-369.

108. Fabiana ChanSalum T, Villeneuve P, Barea B, et al. Synthesis of biodiesel in column fixed-bioreactor using the fermented solid produced by Burkholderia cepacia LTEB11. Process Biochemistry. 2010;45(8):13481354.

109. Ruohang Wang, Shalyda Md Shaarani, Leticia Casas Godoy, et al. Bioconversion of rapeseed meal for the production of a generic microbial feedstock. Enzyme and Microbial Technology. 2010;47(3):77-83.

110. Ali HKQ, Zulkali MMD. Design aspects of bioreactors for solid-state fermentation: A review. Chemical and biochemical engineering quarterly. 2011;25(2):255-266.

111. Prabhakar A, Krishnaiah K, Janaun J, et al. An overview of engineering aspects of solid state fermentation. Malaysian Journal of Microbiology. 2005;1(2):10-16.

112. Stuart DM, Mitchell DA. Mathematical model of heat transfer during solid-state fermentation in well-mixed rotating drum bioreactors. $J$ Chem Technol Biotechnol. 2003;78(11):1180-1192.

113. Sindhu R, Pandey A, Binod P. Solid-state fermentation for the production of poly(hydroxyalkanoates). Chemical and biochemical engineering quarterly. 2015;29(2):173-181.

114. Moebus O, Teuber M. Production of ethanol by solid particles of Saccharomyces cerevisiae in a fluidized bed. European journal of applied microbiology and biotechnology. 1982;15(3):194-197.

115. Foong CW, Janaun J, Krishnaiah K, et al. Effect of superficial air velocity on solid state fermentation of palm kernel cake in a lab scale fermenter using locally isolated fungal strain. Industrial Crops and Products. 2009;30(1):114-118.

116. Foong CW, Krishnaiah K, Janaun J, et al. Heat and mass transfer studies of palm kernel cake (PKC) in fluidized bed fermenter. Industrial Crops and Products. 2009;30(2):227-234.

117. Jang HD, Yang SS. Polyunsaturated fatty acids production with a solid-state column reactor. Bioresour Technol. 2008;99(14):6181-6189.

118. Olazar M, Alvarez S, Aguado R, et al. Spouted bed reactors. Chem Eng Technol. 2003;26(8):845-852.

119. Viswanathan K, Lyall MS, Raychaudhuri BC. Spouted bed drying of agricultural grains. Can J Chem Eng. 2009;64(2):223-232.

120. San José MJ, Alvarez S, Morales A, et al. Solid cross-flow into the spou and particle trajectories in conical spouted beds consisting of solids of different density and shape. Chemical Engineering Research and Design. 2006;84(6):487-494

121. Roman G Szafran, Andrzej Kmiec. CFD modelling of heat and mass transfer in a spouted bed dryer. Ind Eng Chem Res. 2004;43(4):11131124.

122. Faïçal Larachi, Bernard PA Grandjean, Jamal Chaouki. Mixing and circulation of solids in spouted beds: particle tracking and Monte Carlo emulation of the gross flow pattern. Chemical Engineering Science. 2003;58(8):1497-1507.

123. Meghavarnam AK, Janakiraman S. Solid state fermentation: An effective fermentation strategy for production of L-asparaginase by Fusarium culmorum (ASP-87). Biocatalysis and Agricultural Biotechnology. 2017:11:124-130.

124. Cerda A, Gea T, Vargas-García MC, et al. Towards a competitive solid state fermentation: Cellulase production from coffee husk by sequential batch operation and role of microbial diversity. Sci Total Environ. 2017;589:56-65. 
125. Mitchell DA, Von Meien OF. Mathematical modelling as a tool to investigate the design and operation of the zymotis packed bed-bioreactor for solid state fermentation. Biotechnol Bioeng. 2000;68(2):127-135.

126. Garcia-Ochoa F, Gomez E. Bioreactor scale-up and oxygen transfer rate in microbial processes: An overview. Biotechnol Adv. 2009;27(2):153176.

127. Hölker U, Lenz J. Solid-state fermentation are there any biotechnological advantages? Curr Opin Microbiol. 2005;8(3):301-306.

128. Hamidi-Esfahani Z, Shojaosadati SA, Rinzema A. Modelling of simultaneous effect of moisture and temperature on A. niger growth in solid-state fermentation. Biochemical Engineering Journal. 2004;21(3):265-272.

129. De Almeida FP, Freire DMG, Lins U, et al. Surface imaging of the filamentous fungus Penicillium simplicissimum growing in a solid-satte fermentation system. Micron. 2017;99:19-25.

130. Pedro Jiménez-Peñalver, Teresa Gea, Antoni Sánchez, et al. Production of sophorolipids from winterization oil cake by solid-state fermentation: Optimization, monitoring and effect of mixing. Biochemical Engineering Journal. 2017;115:93-100.

131. Schutyser MA, De Pagter P, Weber FJ, et al. Substrate aggregation due to aerial hyphae during discontinuously mixed solid-state fermentation with Aspergillus oryzae: Experiments and modelling. Biotechnol Bioeng. 2003;83(5):503-513.

132. Schutyser MA, Weber FJ, Briels WJ, et al. Heat and water transfer in a rotating drum containing solid substrate particle. Biotechnol Bioeng. 2003;82(5):552-563.
133. Hölker U, Höfer M, Lenz J. Biotechnological advantages of laboratory-scale solid-state fermentation with fungi. Appl Microbiol Biotechnol. 2004;64(2):175-186.

134. Kalogeris E, Iniotaki F, Topakas E, et al. Performance of an intermittent agitation rotating drum type bioreactor for solid-state fermentation of wheat straw. Bioresour Technol. 2003;86(3):207-213.

135. David A Mitchell, Oscar F von Meien, Nadia Krieger, et al. A review of recent developments in modelling of microbial growth kinetics and intraparticle phenomena in solid-state fermentation. Biochemical Engineering Journal. 2004;17(1):15-26.

136. Nagel FJJI, Tramper J, Bakker MSN, et al. Model for on-line moisture-content control during solid-state fermentation. Biotechnology and Bioengineering. 2001;72(2):232-243.

137. Gervais P, Bensoussan M, Grajek W. Water activity and water content: comparative effects on the growth of Penicillium roqueforti on solid substrate. Applied Microbiology and Biotechnology. 1998;27(4):389-392.

138. Gibson AM, Baranyi J, Pitt JI, et al. Predicting fungal growth: The effect of water activity on Aspergillus flavus and related species. Int J Food Microbiol. 1994;23(3-4):419-431.

139. Patrick Gervais. Water activity: a fundamental parameter of aroma production by microorganisms. Applied Microbiology and Biotechnology. 1990;33(1):72-75 